OPEN ACCESS

Edited by:

Shashi Kant Bhatia,

Konkuk University, South Korea

Reviewed by:

Rakshak Kumar,

Institute of Himalayan Bioresource

Technology (CSIR), India

Tania Pozzo,

University of California, Davis,

United States

*Correspondence:

Xukai Jiang

xukai.jiang@sdu.edu.cn

Min Xiao

minxiao@sdu.edu.cn

Specialty section:

This article was submitted to

Microbiotechnology,

a section of the journal

Frontiers in Microbiology

Received: 21 July 2021 Accepted: 06 September 2021

Published: 12 October 2021

Citation:

Yan Z, Cao X, Yang $X$, Yang $S$, $X u L$, Jiang $X$ and Xiao $M$ (2021) A

Novel $\beta$-Glucosidase From

Chryseobacterium scophthalmum

1433 for Efficient Rubusoside

Production From Stevioside.

Front. Microbiol. 12:744914.

doi: 10.3389/fmicb.2021.744914

\section{A Novel $\beta$-Glucosidase From Chryseobacterium scophthalmum 1433 for Efficient Rubusoside Production From Stevioside}

\author{
Zhenxin Yan ${ }^{1}$, Xueting $\mathrm{Cao}^{1}$, Xiao Yang ${ }^{1}$, Shida Yang ${ }^{1}, \mathrm{Li} \mathrm{Xu}^{2}$, Xukai Jiang ${ }^{2 *}$ and \\ Min Xiao ${ }^{1,2 *}$
}

'State Key Laboratory of Microbial Technology, Shandong University, Qingdao, China, ${ }^{2}$ National Glycoengineering Research Center, Shandong Key Laboratory of Carbohydrate Chemistry and Glycobiology, NMPA Key Laboratory for Quality Research and Evaluation of Carbohydrate-Based Medicine, Shandong University, Qingdao, China

As a natural sweetening and solubilizing agent, rubusoside has great potential in the application of healthy beverages and pharmaceuticals. However, the direct extraction and purification of rubusoside from raw materials is inefficient. In this work, a novel $\beta$-glucosidase (CsBGL) was obtained from Chryseobacterium scophthalmum 1433 through screening of the environmental microorganisms. CsBGL markedly hydrolyzed sophorese (Glc $\beta 1-2 \mathrm{Glc}$ ) and laminaribiose (Glc $\beta 1-3 \mathrm{Glc})$, but for steviol glycosides, it only hydrolyzed the C-13/C-19-linked sophorese, instead of the C-13/C-19-linked Glc $\beta 1-2[G \mid c \beta 1-3]$ Glc trisaccharide and Glc $\beta 1$-monosaccharide. It efficiently hydrolyzed stevioside $(240 \mathrm{~g} / \mathrm{L})$ to produce rubusoside $\left(99 \%\right.$ yield) at $47.5^{\circ} \mathrm{C}$ for $70 \mathrm{~min}$. Even when using a crude steviol glycosides extract (500 g/L) containing $\sim 226 \mathrm{~g} / \mathrm{L}$ stevioside as the substrate, CsBGL could also convert stevioside to rubusoside (99\% yield) at $47.5^{\circ} \mathrm{C}$ for $2 \mathrm{~h}$, in which the rubusoside concentration increased from the initial $42 \mathrm{~g} / \mathrm{L}$ to the final $222 \mathrm{~g} / \mathrm{L}$. These results reveal that CsBGL would be a promising biocatalyst for the industry-scale production of rubusoside from stevioside or/and the crude steviol glycosides extract.

Keywords: $\beta$-glucosidase, rubusoside, stevioside, crude steviol glycosides extract, Chryseobacterium scophthalmum

\section{INTRODUCTION}

Rubusoside is a natural non-caloric sweetener and mainly extracted from Rubus suavissimus S. Lee which only grows in the southern area of China (Ko et al., 2012). It is approximately 114 times sweeter than sucrose (Darise et al., 1984) and displays diverse bioactivities, such as hypoglycemic, antiallergic, anticariogenic, and antiangiogenic functions (Liu et al., 2006, 2020; Kim et al., 2019; Wang et al., 2020). Therefore, rubusoside has been widely used as an additive to herbal tea and healthy beverages. On the other hand, the amphipathicity of rubusoside makes it a natural solubilizer to enhance the solubility of various pharmaceutical compounds, including paclitaxel, resveratrol, curcumin, capsaicin, cyclosporine, nystatin, etoposide, and erythromycin (Ko et al., 2012; Zhang et al., 2012, 2017). However, the direct extraction and purification of rubusoside from the dried leaves of R. suavissimus $\mathrm{S}$. Lee is laborious and time-consuming due to its fractional content in raw materials $(\sim 5 \%)$ (Chou et al., 2009; Wang et al., 2015). Therefore, the large-scale industrial production of rubusoside remains challenging. 


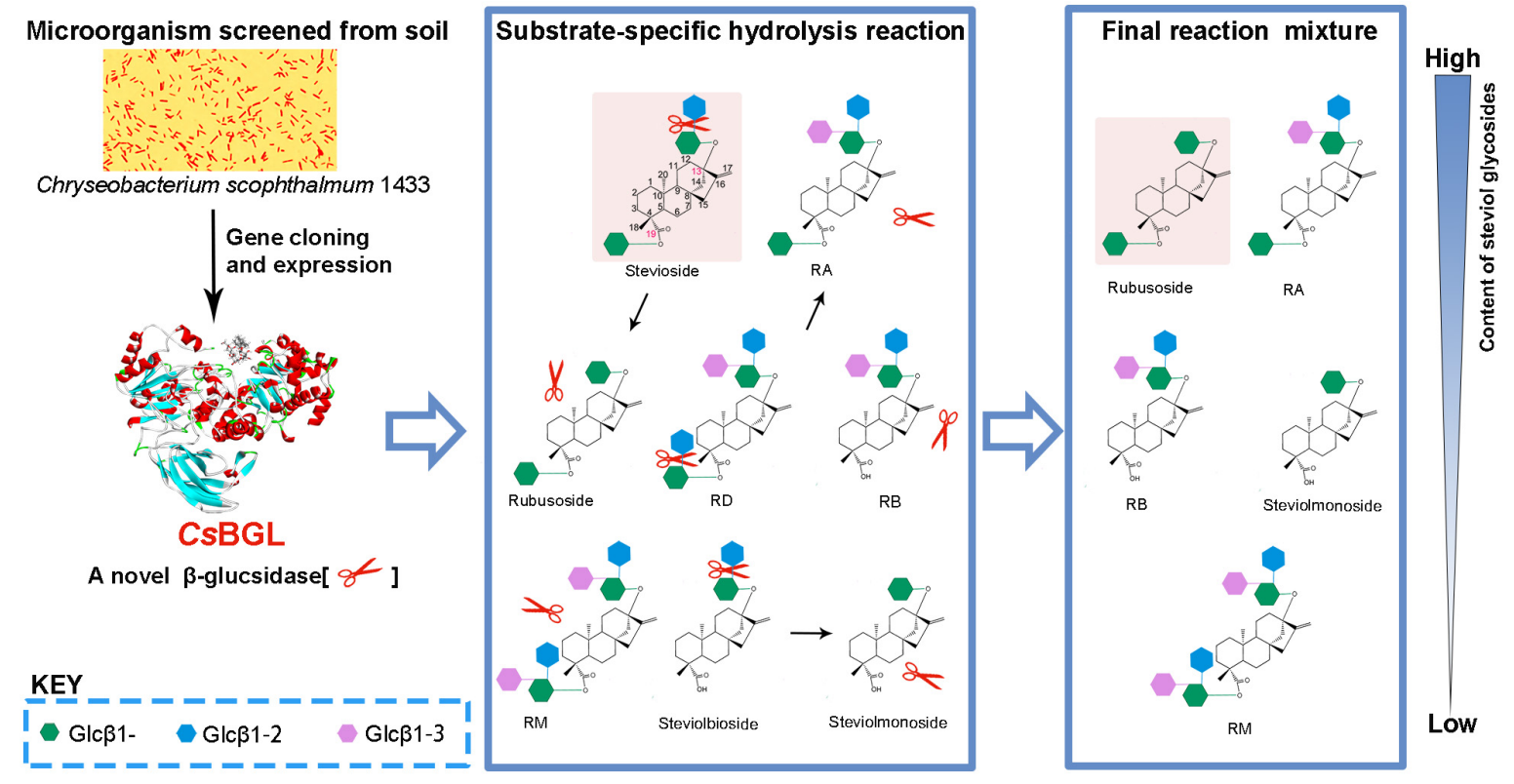

GRAPHICAL ABSTRACT | As a natural sweetening and solubilizing agent, rubusoside has great potential in the application of healthy beverages and pharmaceuticals. A novel $\beta$-glucosidase CsBGL obtained here from Chryseobacterium scophthalmum 1433 through screening of the environmental microorganisms could specifically hydrolyze the C-13- or/and C-19-linked sophorese of steviol glycosides, but not the C-13- or/and C-19-linked Glc $\beta 1$-2[Glc $\beta 1$-3]Glc trisaccharide and Glc $\beta 1$-monosaccharide of steviol glycosides, and thus could be a promising biocatalyst for efficient rubusoside production from stevioside.

Rubusoside is a minor component of steviol glycosides which belong to tetracyclic diterpene glycosides extracted from the leaves of the Stevia rebaudiana Bertoni. The US Food and Drug Administration and the European Food Safety Authority have identified steviol glycosides as "generally recognized as safe" (GRAS) compounds (Gerwig et al., 2016). Stevioside is the major component of steviol glycosides and has been manufactured commercially since the 1970s (Ko et al., 2012). Stevioside and rubusoside share the same skeleton; the only difference is that stevioside has an additional $\beta$-D-glucopyranosyl unit in a $\beta$ 1,2-linkage at the C-13 hydroxyl group. Therefore, it is feasible to convert stevioside into rubusoside by selectively cleaving the extra glucopyranosyl unit at the C-13 hydroxyl group of stevioside (Ko et al., 2012; Wan et al., 2012; Wang et al., 2015; Lan et al., 2019).

Several $\beta$-glucosidases and $\beta$-galactosidases were found to be able to hydrolyze the $\beta$-1,2-glucosidic bond in the sophorosyl disaccharide at the $\mathrm{C}-13$ hydroxyl group of stevioside (Ko et al., 2012; Wan et al., 2012; Nguyen et al., 2014; Boonkaew et al., 2019). Unfortunately, most of these enzymes, for example, SSGase from Sigma-Aldrich's commercial enzyme cocktails (Ko et al., 2012) $\beta$-galactosidase from Aspergillus sp. CICIMF0620 (Wan et al., 2012) and lactase from Thermus thermophilus (Nguyen et al., 2014) display promiscuous hydrolysis activity to stevioside and other steviol glycosides, including rubusoside. This inevitably decreases the yield of rubusoside because the rubusoside produced is further hydrolyzed. Although past studies claimed that BGL1 from Streptomyces sp. GXT6 and SPBGL1 from Sphingomonas elodea ATCC 3146 specifically hydrolyze stevioside to rubusoside and have no hydrolysis activity to rubusoside (Wang et al., 2015; Lan et al., 2019) the reactions catalyzed by these two enzymes took a long time of $6 \mathrm{~h}$ to achieve the highest yield of rubusoside. To meet the increasing demand for rubusoside, it becomes essential to find novel enzymes with better substrate specificity and catalytic properties.

The present study aims to discover novel enzymes and explore the optimal catalysis-based reaction system for production of rubusoside from stevioside. Through screening the soil microorganisms, we isolated a new strain of Chryseobacterium scophthalmum 1433 which was able to produce a novel $\beta$-glucosidase (named CsBGL). CsBGL showed strict hydrolytic specificity to the $\beta$-1,2-glucosidic bond in the sophorosyl disaccharide without $\beta$-1,3-glucosidic bond branch and did not hydrolyze the single $\beta$-D-glucopyranosyl unit in steviol glycosides. The enzyme could efficiently produce rubusoside using stevioside and/or the crude steviol glycosides extract as the substrates, with 99\% conversion of stevioside and 99\% yield of rubusoside, providing a great potential as an efficient catalyst for the industrial-scale production of rubusoside.

\section{MATERIALS AND METHODS}

\section{Materials and Enzymes}

Rebaudioside D (RD), Rebaudioside M (RM), Rebaudioside A (RA), stevioside, and the crude steviol glycosides extract containing about $45 \%$ stevioside were gifts from Zhucheng Haotian Pharm Co., Ltd. (Weifang, China). Rubusoside and steviol were purchased from Chengdu Herbpurify Co., 
Ltd. (Chengdu, China). Steviolmonoside, steviolbioside, and Rebaudioside B (RB) were prepared by alkaline hydrolysis from rubusoside, stevioside, and RA, respectively, with $0.5 \mathrm{~N} \mathrm{NaOH}$ at $100^{\circ} \mathrm{C}$ for $15 \mathrm{~min}$ in this work (Nakano et al., 1998). $p$-Nitrophenyl- $\beta$-D-glucopyranoside ( $p$ NP$\beta$-Glc), $p$-nitrophenyl-N-acetyl- $\beta$-D-glucosamine $(p \mathrm{NP}-\beta$-Glc NAc), $p$-nitrophenyl- $\beta$-D-glucuronic acid ( $p$ NP- $\beta$-GlcA), $p$-nitrophenyl- $\beta$-D-galactopyranoside $(p \mathrm{NP}-\beta-\mathrm{Gal}), \quad p$-nitro -phenyl- $\beta$-fucose $\quad(p$ NP- $\beta$-Fuc $), \quad p$-nitrophenyl- $\beta$-manno -pyranoside ( $p$ NP- $\beta$-Man), $p$-nitrophenyl- $\alpha$-D-glucopyranoside $(p \mathrm{NP}-\alpha-\mathrm{Glc})$, and $p$-nitrophenyl- $\alpha$-D-galactopyranoside ( $p \mathrm{NP}$ $\alpha-\mathrm{Gal}$ ) were purchased from Sigma-Aldrich (United States). Esculin, cellobiose, laminaribiose, and gentiobiose were purchased from J\&K Scientific Co., Ltd. (Beijing, China). The Phusion DNA polymerase was KOD-Plus-Neo from Toyobo Co., Ltd., Life Science Department (Osaka, Japan). T5 Exonuclease and restriction enzymes were from New England Bio-Labs. Glucose Assay Kit was from Biosino Bio-Technology and Science Inc. (Beijing, China). The other chemicals used were analytical grade.

\section{Strains and Media}

Chryseobacterium scophthalmum 1433 was isolated from a soil sample in a wood. The selective medium was the modified M9 medium, containing $0.5 \mathrm{~g} \mathrm{NH}_{4} \mathrm{Cl}, 3.0 \mathrm{~g} \mathrm{Na}_{2} \mathrm{HPO}_{4}, 1.5 \mathrm{~g} \mathrm{KH}_{2} \mathrm{PO}_{4}$, $1 \mathrm{mM} \mathrm{MgSO}_{4}$, and $15 \mathrm{~g}$ stevioside in $1 \mathrm{~L}$ ultrapure water $(\mathrm{pH}$ 7.4). C. scophthalmum 1433 has been deposited in the China General Microbiological Culture Collection Center (CGMCC) with an accession number CGMCC 20188. Escherichia coli strain $\mathrm{BL} 21$ (DE3) harboring plasmids were cultured at $37^{\circ} \mathrm{C}$ in $\mathrm{LB}$ medium with $50 \mu \mathrm{g} / \mathrm{ml}$ kanamycin.

\section{Isolation and Identification of Microorganism}

The collected soil sample (1 g) was suspended in $10 \mathrm{ml}$ sterile water, and the suspension was serially diluted and spread on selective media plates. After incubating at $30^{\circ} \mathrm{C}$ for 7 days, 48 colonies with distinct morphological features were isolated and cultured in liquid selective media at $30^{\circ} \mathrm{C}$ with shaking at $200 \mathrm{rpm}$ for 7 days. The cultured supernatant was analyzed by thin layer chromatography (TLC) for the hydrolyzed product of stevioside. A colony with the hydrolysis activity to stevioside was selected and its pure culture (strain 1433) was obtained by the streak plate method.

The draft genome of strain 1433 was sequenced on the Illumina HiSeq 4000 platform performed by Sangon Biotech Co., Ltd. (Shanghai, China). Raw reads were generated through base calling, which transforms pyroluminescence intensity signals into nucleotide sequences. High-quality clean reads were obtained by stringently filter raw reads using SOAPnuke software. ${ }^{1}$ The phred quality score should be more than 30 (base call accuracy more than 99.9\%). Clean reads were assembled by SPAdes (Bankevich et al., 2012) and the gaps of contigs were repaired by GapFiller (Boetzer and Pirovano, 2012). The proteome of strain 1433 was predicted based on its draft genome. The sequence

\footnotetext{
${ }^{1}$ https://github.com/BGI-flexlab/SOAPnuke
}

has been deposited in GenBank with an accession number JAFLHF000000000.1. The draft-genome phylogenomic tree was constructed with the CVTree 3.0 server using the parameterfree and whole-genome-based compositional vector algorithm (Zuo and Hao, 2015). Elizabethkingia miricola was used as the outgroup in the phylogenetic analysis. The full-length 16S rRNA gene sequence of strain 1433 (GenBank no. MW689256.1) was generated from the draft genome. Sequence identity analysis was performed using BLAST. ${ }^{2}$

\section{Peptide Mapping and Sequence Analysis of $\beta$-Glucosidase}

Cells of C. scophthalmum 1433 were harvested from the selection medium by centrifugation. The culture solution was concentrated and washed by ultrafiltration. The cells were lysed through sonication, and the lysate was centrifuged at $15,000 \times g$ for $15 \mathrm{~min}$ at $4^{\circ} \mathrm{C}$. The culture solution, cells, and soluble-lysate were used for stevioside hydrolysis test at $37^{\circ} \mathrm{C}$ for $10 \mathrm{~min}$ in $50 \mathrm{mM}$ sodium phosphate buffer ( $\mathrm{pH}$ 7.4). The soluble-lysate was used as the crude enzymes in native acidic polyacrylamide gel electrophoresis (native acidic PAGE) (Pompeu et al., 2015). The native electrophoresis under acidic conditions was performed using 3.1\% stacking gel and 7.7\% running gel. The electrophoretic run (Mini-PROTEAN, Bio-Rad, Hercules, CA, United States) was performed at $4^{\circ} \mathrm{C}$. A pre-race was performed under a constant current of $3.0 \mathrm{~mA}$ for $30 \mathrm{~min}$, and then samples were loaded and the electrodes were reversed under constant voltage of $120 \mathrm{~V}$ for $3 \mathrm{~h}$. Proteins in the gel were visualized by Coomassie brilliant blue (CBB) R-250 staining. The $\beta$-glucosidase activity in the gel was detected by staining with a chromogenic solution containing $0.5 \%(\mathrm{w} / \mathrm{v})$ esculoside and $0.05 \%(\mathrm{w} / \mathrm{v})$ ferric ammonium citrate at $40^{\circ} \mathrm{C}$ for $15 \mathrm{~min}$ (Edberg et al., 1976). The brown band in the gel was excised and cut to $\sim 1 \mathrm{~mm}^{3}$ slices and decolorized by sequentially washing with ultrapure water, $100 \mathrm{mM} \mathrm{NH} \mathrm{HCO}_{3}, 50 \%$ acetonitrile, and $100 \%$ acetonitrile. Subsequently, the gel slices were reduced by $20 \mathrm{mM}$ dithiothreitol at $55^{\circ} \mathrm{C}$ for $1 \mathrm{~h}$, alkylated by $100 \mathrm{mM}$ iodoacetamide, avoiding light at $25^{\circ} \mathrm{C}$ for $30 \mathrm{~min}$, digested by $10 \mathrm{ng} / \mu \mathrm{l}$ trypsin at $37^{\circ} \mathrm{C}$ for $12 \mathrm{~h}$, extracted by ultrasonic method for $1 \mathrm{~h}$, and desalted by C18 ZipTip pipette tips (Jinao et al., 2017). Then the digested peptides were analyzed by prominent nano LC-LTQ orbitrap velos pro ETD; the mass spectral data were searched against the predictive proteome of C. scophthalmum 1433 by the Proteome Discoverer Software Work Station 2.3.

The amino acid sequences of CsBGL were used to perform the multiple sequence alignment with three reported $\beta$-glucosidases that have hydrolysis activity to stevioside, including BGL1 from Streptomyces sp. GXT6 CGMCC 7091 (GenBank no. KJ958924), (Wang et al., 2015) SPBGL1 from S. elodea ATCC 31461 (GenBank no. WP_029622673.1), (Lan et al., 2019) and EcBgl from Enterococcus casseliflavus strain EC20 (GenBank no. ECBG_01478), (Boonkaew et al., 2019) and three well studied GH3 $\beta$-glucosidases including JMB19063 from a compost metagenome (PDB code: 3U48), (McAndrew et al., 2013) BtBGL

\footnotetext{
${ }^{2}$ http://www.ncbi.nlm.nih.gov/BLAST/
} 
from Bacteroides thetaiotaomicron (PDB code: 5xxn), (Ishiguro et al., 2017) and LiBGL from Listeria innocua (GenBank no. CAC97071.1) (Nakajima et al., 2016). Clustal X was used to conduct multiple sequence alignment. ${ }^{3}$

Homology modeling of CsBGL was performed using SWISS$\mathrm{MODEL}^{4}$, and the 3D structure of BtBGL (PDB code: $5 \mathrm{xxn}$ ) from $B$. thetaiotaomicron served as the template (Ishiguro et al., 2017). CsBGL shared $60.9 \%$ sequence identity with the template. The docking studies of the interaction between the CsBGL and stevioside were carried out using Autodock4.2.6. ${ }^{5}$ The docking results were generated and the best conformational pose was scrutinized for analysis by PyMol 1.3. The interactions and the binding affinities of CsBGL and stevioside complex were also analyzed and visualized with PyMol 1.3.

\section{Gene Cloning and Heterogeneous Expression}

$\mathrm{N}$-terminal signal peptide of the putative $\beta$-glucosidase CsBGL was predicted in SignalP-5.0 Server. ${ }^{6}$ The genomic DNA of C. scophthalmum 1433 was extracted and used as the template for PCR. The primers were designed based on the gene sequence of CsBGL without signal peptides. The sequence of forward and reverse primers were $5^{\prime}$ GGGTCGCGGATCCGAACAGGAAATGGTTACAAAGCC-3' and $5^{\prime}$-CGAGTGCGGCCGCAAGTTTCGTCCAGTTGATTTT TG-3'; the homologous ends (underlined) were used for the construction of expression plasmid of pET28a-CsBGL. The PCR procedures consisted of an initial denaturation step at $94^{\circ} \mathrm{C}$ for $5 \mathrm{~min}, 30$ replication cycles $\left(94^{\circ} \mathrm{C}\right.$ for $20 \mathrm{~s}, 60^{\circ} \mathrm{C}$ for $15 \mathrm{~s}$, and $68^{\circ} \mathrm{C}$ for $90 \mathrm{~s}$ ), and a final extension step at $68^{\circ} \mathrm{C}$ for $10 \mathrm{~min}$. The PCR products were purified and assembled with the linearized expression plasmid pET28a by T5 Exonuclease, (Xia et al., 2019) and transformed into E. coli BL21(DE3). The proper transformants were incubated at $37^{\circ} \mathrm{C}$ in $\mathrm{LB}$ medium with $50 \mu \mathrm{g} / \mathrm{ml}$ kanamycin; when the cell density reached 0.8 at $600 \mathrm{~nm}, 0.1 \mathrm{mM}$ of isopropyl- $\beta$-D-thiogalactopyranoside (IPTG) was added to induce the expression of recombinant CsBGL. After continuous cultivation for $5 \mathrm{~h}$, the cells were harvested and lysed by sonication. The lysate was centrifuged at $15,000 \times g$ for $15 \mathrm{~min}$ at $4^{\circ} \mathrm{C}$ and the supernatant was subjected to enzyme purification through nickel affinity chromatography. The purified protein samples were detected by $10 \%(\mathrm{w} / \mathrm{v})$ of sodium dodecyl sulfate polyacrylamide gel electrophoresis (SDS-PAGE), (Brunelle and Green, 2014) and proteins in the gel were visualized by CBB R-250 staining.

\section{Enzyme Assays}

The $\beta$-glucosidase activity was measured by mixing $5 \mu$ l enzyme solution with $45 \mu \mathrm{l} 2 \mathrm{mM} p \mathrm{NP}-\beta-\mathrm{Glc}$ in $50 \mathrm{mM}$ sodium phosphate buffer ( $\mathrm{pH} 7.4$ ) and then incubated at $45^{\circ} \mathrm{C}$ for $5 \mathrm{~min}$. The reaction was stopped by addition of $100 \mu \mathrm{l} 1 \mathrm{M} \mathrm{Na}_{2} \mathrm{CO}_{3}$ solution. The liberated $p$-nitrophenol was measured at $405 \mathrm{~nm}$

\footnotetext{
${ }^{3}$ http://www.clustal.org/

${ }^{4}$ https://swissmodel.expasy.org/interactive

${ }^{5}$ http://autodock.scripps.edu/

${ }^{6}$ http://www.cbs.dtu.dk/services/SignalP/index.php
}

by a Synergy LX microplate reader (BioTek, United States) in 96-well microtiter plates. One unit of enzyme activity (U) was defined as the amount of enzyme required to liberate $1 \mu \mathrm{mol} p$-nitrophenol per minute under the assay condition. Activity assays were also performed for other nitrophenyl glycosides under the same conditions, including $p \mathrm{NP}-\beta-\mathrm{Glc}$, $p$ NP- $\beta$-GlcNAc, $p$ NP- $\beta$-GlcA, $p$ NP- $\beta$-Gal, $p$ NP- $\beta$-Fuc, $p$ NP$\beta$-Man, $p$ NP- $\alpha-$ Glc, and $p N P-\alpha-$ Gal. Protein concentration was determined according to the Bradford assay protocol (Zuo and Lundahl, 2000), with bovine serum albumin (BSA) as standard.

\section{Biochemical Characterization}

The substrate specificity of CsBGL was determined by incubating the enzyme $(0.5 \mathrm{U} / \mathrm{ml})$ with $5 \mathrm{mM}$ various substrates under the enzyme assay conditions. The reaction was terminated by boiling for $5 \mathrm{~min}$ and the released glucose was determined by Glucose Assay Kit with glucose as a standard. The hydrolysis products from steviol glucosides were determined by high performance liquid chromatography (HPLC).

The optimal $\mathrm{pH}$ of $\mathrm{CsBGL}$ was determined by measuring the enzyme activity with $p \mathrm{NP}-\beta$-Glc at gradient $\mathrm{pH}$ values ranging from 3.5 to 8.0 in $100 \mathrm{mM}$ sodium hydrogen phosphate-citric acid buffer, 8.0-9.0 in $50 \mathrm{mM}$ Tris- $\mathrm{HCl}$ buffer, and 9.0-10.5 in $50 \mathrm{mM}$ glycine-sodium hydroxide buffer. The $\mathrm{pH}$ stability of CsBGL was determined by incubating the enzyme in the presence of the above various buffers at $4^{\circ} \mathrm{C}$ for $24 \mathrm{~h}$ and measuring the residual enzyme activity. The optimal temperature of CsBGL was determined by measuring the enzyme activity with $p \mathrm{NP}-\beta$-Glc at gradient temperatures from 30 to $50^{\circ} \mathrm{C}\left(2.5^{\circ} \mathrm{C}\right.$ intervals) for $5 \mathrm{~min}$. The temperature stability of CsBGL was determined by incubating the enzyme at $40,42.5$, and $45^{\circ} \mathrm{C}$ for $15 \mathrm{~min}$ to $240 \mathrm{~min}$ and measuring the residual enzyme activity. Furthermore, the effects of metal ions including $\mathrm{AgNO}_{3}$, $\mathrm{KCl}, \mathrm{LiCl}, \mathrm{HgCl}_{2}, \mathrm{CuSO}_{4}, \mathrm{CrSO}_{4}, \mathrm{MnCl}_{2}, \mathrm{CaCl}_{2}, \mathrm{NiSO}_{4}, \mathrm{FeCl}_{2}$, $\mathrm{FeCl}_{3}, \mathrm{CoSO}_{4}$, and $\mathrm{ZnSO}_{4}$ were explored through determining the enzyme activity in the presence of $2 \mathrm{mM}$ metal salts. All the experiments were carried out in triplicate.

The initial reaction velocity was measured by incubating CsBGL $(0.77 \mathrm{U} / \mathrm{ml})$ in $50 \mu \mathrm{l} 50 \mathrm{mM}$ sodium phosphate buffer ( $\mathrm{pH} 7.4$ ) containing $0,20,40$, and $80 \mathrm{mM}$ glucose and $0.1-$ $10 \mathrm{mM} p \mathrm{NP}-\beta$-Glc under the enzyme assay conditions and the enzyme activity was examined. $K_{m}, k_{\text {cat }}$, and $K_{i}$ were calculated in GraphPad Prism 8 software. All the experiments were carried out in triplicate.

\section{Production and Isolation of Rubusoside}

The conditions to produce rubusoside from stevioside were explored using $600 \mu \mathrm{g} / \mathrm{ml}(30.9 \mathrm{U} / \mathrm{ml})$ enzyme and $240 \mathrm{~g} / \mathrm{L}$ stevioside. The effects of $\mathrm{pH}$ values were examined at $45^{\circ} \mathrm{C}$ for $40 \mathrm{~min}$ at various $\mathrm{pH}$ values from 5 to 8.0 in $100 \mathrm{mM}$ sodium hydrogen phosphate-citric acid buffer, 8.0-9.0 in $50 \mathrm{mM}$ Tris$\mathrm{HCl}$ buffer, and $9.0-10$ in $50 \mathrm{mM}$ glycine-sodium hydroxide buffer. The effects of temperature were examined in $50 \mathrm{mM}$ sodium phosphate buffer $(\mathrm{pH}$ 6.5) for $40 \mathrm{~min}$ at different temperatures ranging from 35 to $50^{\circ} \mathrm{C}$ with $2.5^{\circ} \mathrm{C}$ intervals. The time-course analysis was performed in $1 \mathrm{ml} 50 \mathrm{mM}$ sodium phosphate buffer $(\mathrm{pH} 6.5)$ at $47.5^{\circ} \mathrm{C}$ for $5-120 \mathrm{~min}$, and the 
sample $(50 \mu \mathrm{l})$ was taken out with $5-10$-min intervals. Using the crude steviol glycosides extract as the substrate, we used $1 \mathrm{~L}$ reaction mixture containing $500 \mathrm{~g}$ crude steviol glycosides extract and $300 \mu \mathrm{g} / \mathrm{ml}(15.5 \mathrm{U} / \mathrm{ml}) \mathrm{CsBGL}$ in $50 \mathrm{mM}$ sodium phosphate buffer ( $\mathrm{pH} 6.5$ ) at $47.5^{\circ} \mathrm{C}$ for $2 \mathrm{~h}$. The reaction was stopped by boiling for $5 \mathrm{~min}$, and the glucose released was detected using the Glucose Assay Kit, and the hydrolysis products were identified by HPLC analysis.

Rubusoside was isolated by gel filtration chromatography on a Bio-Gel P2 column $(3.5 \times 120 \mathrm{~cm})$ with distilled water as the eluent. The eluted fractions were collected and monitored by TLC, and the identified fractions were combined and concentrated by evaporation and lyophilized to dry powder.

The conversion of stevioside (molar ratio) was calculated by dividing the concentration of converted stevioside by its initial concentration. The yield of rubusoside (molar ratio) was calculated through dividing the concentration of produced rubusoside by the initial concentration of stevioside.

\section{High Performance Liquid Chromatography and Thin Layer Chromatography Analysis}

HPLC was performed by an Agilent 1260 series coupled with a UV detector (G1314B) using a C18 analysis column (Agilent poroshell $120 \mathrm{EC}-\mathrm{C} 18,150 \times 4.6 \mathrm{~mm}, 4 \mu \mathrm{m})$ at $40^{\circ} \mathrm{C}$. Samples were detected by the UV absorbance at $210 \mathrm{~nm}$. The binary mobile phase included solvent A (10 mM KH${ }_{2} \mathrm{PO}_{4}$ solution in water, $0.1 \% \mathrm{TFA}$ ) and solvent $\mathrm{B}$ (acetonitrile, $0.1 \% \mathrm{TFA}$ ) at a flow rate of $0.4 \mathrm{ml} / \mathrm{min}$ for $35 \mathrm{~min}$. The acetonitrile concentrations were changed as follows: $36 \%$ (1-7 $\mathrm{min}), 36-$ $80 \%$ (7-12 $\mathrm{min}), 80 \%$ (12-16 $\mathrm{min}), 80-90 \%$ (16-17 $\mathrm{min}$ ), 90\% (17-20 $\mathrm{min}$ ), 90-36\% (20-25 $\mathrm{min}$ ), after running $10 \mathrm{~min}$ (Wang et al., 2021).

TLC was performed by loading samples on silica gel 60 F254 plates (Merck, Germany). The developing solvent was a mixture of chloroform/methanol/water (8:5:1, v/v/v) (Richman et al., 2005). The chromogenic reagent was $0.5 \%(\mathrm{w} / \mathrm{v}) 3,5-$ dihydroxytoluene in $20 \%(\mathrm{v} / \mathrm{v})$ sulfuric acid. The chromogenic condition was heating at $125^{\circ} \mathrm{C}$ for $4 \mathrm{~min}$.

\section{Mass Spectrometry and Nuclear Magnetic Resonance}

The MS analysis of steviol glycosides including RD, RA, stevioside, rubusoside, steviolbioside, and steviolmonoside were performed through Shimadzu LCMS-IT-TOF (Kyoto, Japan) equipped with an ESI source in negative ion mode at a resolution of 10,000 full width at half-maximum. The NMR spectra of rubusoside was recorded on Agilent DD2-600 spectrometer at $150 \mathrm{MHz}$ for ${ }^{13} \mathrm{C}$ and $600 \mathrm{MHz}$ for ${ }^{1} \mathrm{H}$ in the mixture of DMSO$\mathrm{d}_{6}(600 \mu \mathrm{L})$ and $\mathrm{D}_{2} \mathrm{O}(20 \mu \mathrm{L})$ at $25^{\circ} \mathrm{C}$. Chemical shifts were expressed in parts per million (ppm) downfield from the internal tetramethylsilane of DMSO- $\mathrm{d}_{6}$. Homonuclear ${ }^{1} \mathrm{H} /{ }^{1} \mathrm{H}$ correlation experiments (COSY and TOCSY) and heteronuclear ${ }^{1} \mathrm{H} /{ }^{13} \mathrm{C}$ correlation experiments (HSQC and HMBC) were run using the standard pulse sequences.

\section{RESULTS}

\section{Isolation and Identification of a Stevioside-Hydrolyzing Microorganism}

Only strain 1433 was isolated from the soil samples using the solid and liquid selective media with stevioside as the sole carbon source. Its pure culture showed yellow, opaque, round, and convex on LB agar plate (Supplementary Figure 1A). The cells were gram-negative, rod-shaped, nonmotile, and non-spore-forming when observed under the microscope (Supplementary Figure 1B). The draft genome of strain 1433 contains $4,324,461$ bp with the $\mathrm{G}+\mathrm{C}$ ratio of $33 \%$ (GenBank no. JAFLHF000000000.1). In total, there were 4,043 coding sequences (CDSs), 65 tRNA genes, and 6 rRNA genes in its genome. Specifically, 52 glycoside hydrolases, 67 glycosyltransferases, 8 polysaccharide lyases, and 49 carbohydrate esterases were predicted according to the gene annotation. The whole-genome-based evolutionary tree of multiple species of Chryseobacterium showed that the isolated strain 1433 is closest to C. scophthalmum DSM16779 and next closest to C. scophthalmum VV8 (Supplementary Figure 1C). The 16S rRNA of strain 1433 (GenBank no. MW689256.1) showed a sequence identity of $99.26 \%$ with the type strain of C. scophthalmum Cl-20 (GenBank no. KC178594.1). All the results suggest that strain 1433 was C. scophthalmum.

\section{Cloning and Heterogeneous Expression of CsBGL}

The analysis of the hydrolysis of stevioside showed that the cells and the soluble-lysate could hydrolyze stevioside while the supernate of the culture could not (Supplementary Figure 2), which indicated that the functional enzyme might mainly exist in cells. In the predictive proteome of C. scophthalmum 1433, we found four putative $\beta$-glucosidases. To identify the enzyme for hydrolysis of stevioside, we employed native acidic PAGE and active staining to determine the $\beta$-glucosidase activity of crude enzymes induced by selection medium (Supplementary Figure 3). Subsequently, mass spectrum was used to identify the sequence of $\beta$-glucosidases by searching against the predictive proteome of C. scophthalmum 1433. The 276 peptides of the brown band in active staining were identified by MS, and 37 unique peptides of the MS results matched the putative $\beta$-glucosidase protein (GenBank no. WP_210150222.1, named CsBGL) with $54.45 \%$ coverage. The gene encoding CsBGL protein was 2,328 nucleotides consisting of 775 amino acids with a predicted molecular mass of $84.7 \mathrm{kDa}$ and an isoelectric point of 8.2. By searching the sequence of CsBGL in the Conserved Domains database of NCBI, it was inferred that CsBGL belonged to glycoside hydrolase family 3 (GH3). A signal peptide of 18 amino acid residues in the $\mathrm{N}$-terminal was predicted by SignalP5.0 Server.

Multiple sequence alignment of CsBGL with three other reported $\beta$-glucosidases with stevioside hydrolysis activity, including BGL1 from Streptomyces sp. GXT6 CGMCC 7091, SPBGL1 from $S$. elodea ATCC 31461, and EcBgl from E. casseliflavus strain EC20, and three well-studied $\beta$-glucosidases 


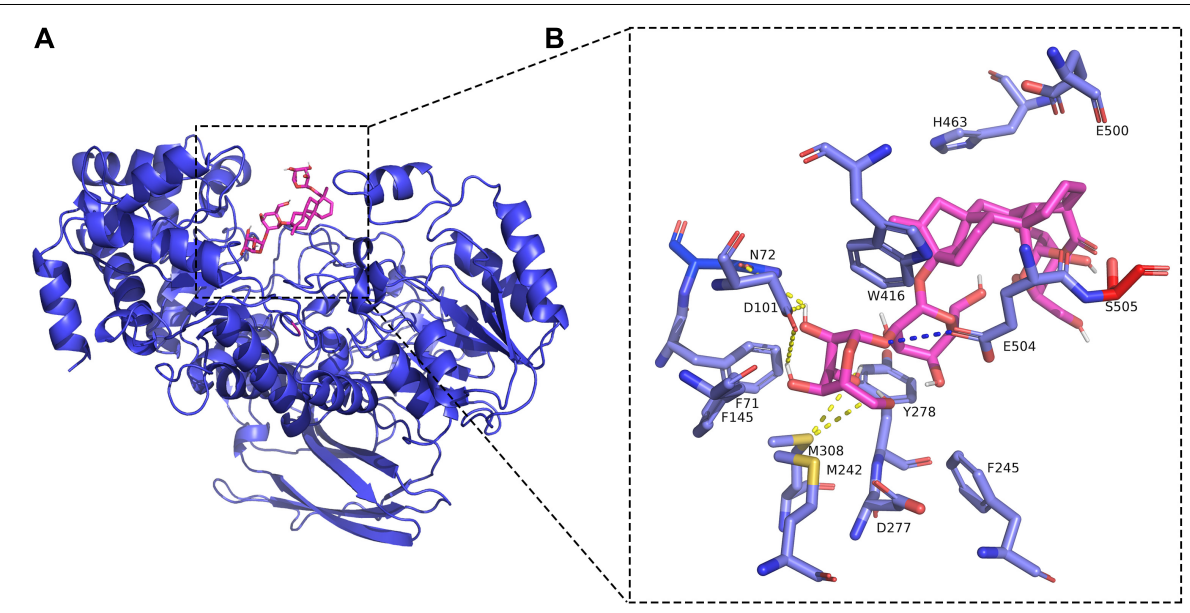

C
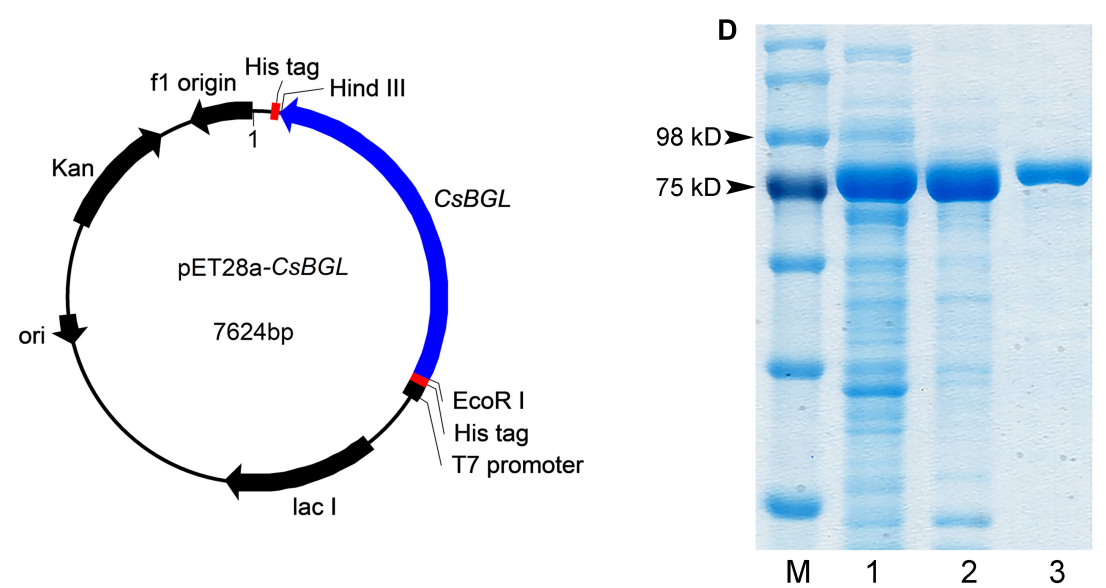

FIGURE 1 | Structure modeling analysis of CsBGL and the heterologous expression of the CsBGL. (A) The putative 3D structure of CsBGL (blue) with stevioside (pink). The structure of CsBGL was modeled using BtBGL (PDB entry 5xxn) from Bacteroides thetaiotaomicron as the template. (B) CsBGL-stevioside interactions. Hydrogen bonds are shown in yellow dotted lines. The unique interaction between E504 (the general acid/base) and glycosidic oxygen is shown in blue dotted line. (C) The map of constructed plasmid of $p E T 28 a-C s B G L$. The cloned gene of CsBGL has 2271 nucleotides without the signal peptide and termination codon. It was inserted between Hindlll and EcoRI of $p$ ET28a plasmid. (D) SDS-PAGE analysis of CsBGL: lane M, protein marker; lane 1, the soluble-lysate after centrifugation; lane 2, the lysate precipitation; lane 3, purified recombinant CsBGL.

of GH3, including JMB19063 from a compost metagenome, BtBGL from B. thetaiotaomicron, and LiBGL from L. innocua, was performed. The results (Supplementary Figure 4) showed that CsBGL employed a conserved aspartate residue (D277) as the catalytic nucleophile and a conserved glutamate residue (E504) as the acid/base residue, which was consistent with the general mechanism of GH3 glucosidases. The full-length amino acid sequence of CsBGL only shared $40.10,41.82$, and $8.50 \%$ identity with SPBGL1 (GH3), EcBgl (GH3), and BGL1 (GH1), respectively. The 3D structure of CsBGL was modeled using BtBGL (PDB entry 5xxn) from B. thetaiotaomicron as the template. The molecular docking of CsBGL with the stevioside as the ligand (Figures 1A,B) showed that N72, D101, and M308 were very important for the binding of stevioside to the enzyme active site. Moreover, E504, the putative catalytic residue as the general acid/base, was precisely oriented to offer the proton for the hydrolysis of the glycosidic bond in the sophorosyl disaccharide of stevioside. The sequence and docking analysis demonstrated that CsBGL was a new $\beta$-glucosidase and could specifically hydrolyze stevioside, respectively.

Then, we successfully constructed a plasmid of $p \mathrm{ET} 28 \mathrm{a}-\mathrm{Cs} B G L$ using the signal-deleted gene of 2,271 nucleotides (Figure 1C) and expressed CsBGL in E. coli BL21(DE3). As shown in Figure 1D, in SDS-PAGE, the purified CsBGL migrated as a single protein band with a molecular mass of approximately $86.3 \mathrm{kDa}$, consistent with the molecular mass prediction of CsBGL without signal peptide $(82.8 \mathrm{kDa})$ which fused with the histidine tag (about $3.5 \mathrm{kDa}$ ).

$C s B G L$ showed the highest activity to $p \mathrm{NP}-\beta-\mathrm{Glc}(51.5 \mathrm{U} / \mathrm{mg})$. $C s \mathrm{BGL}$ also hydrolyzed $p \mathrm{NP}-\beta$-Gal, $p \mathrm{NP}-\alpha-\mathrm{Glc}$, and $p \mathrm{NP}-\alpha-\mathrm{Gal}$ with less than $2 \%$ relative activity of the $p$ NP- $\beta$-Glc. No activity was detected for $p$ NP- $\beta$-GlcNAc, $p$ NP- $\beta$-GlcA, $p N P-\beta$-Fuc, and pNP- $\beta$-Man.

CsBGL retained potent activity at $\mathrm{pH} 7.0-7.5$ and it was stable at $\mathrm{pH}$ 4.0-10.0 (Figures 2A,B). CsBGL showed the best activity at $45^{\circ} \mathrm{C}$ and it showed stability at 40 and $42.5^{\circ} \mathrm{C}$, but 

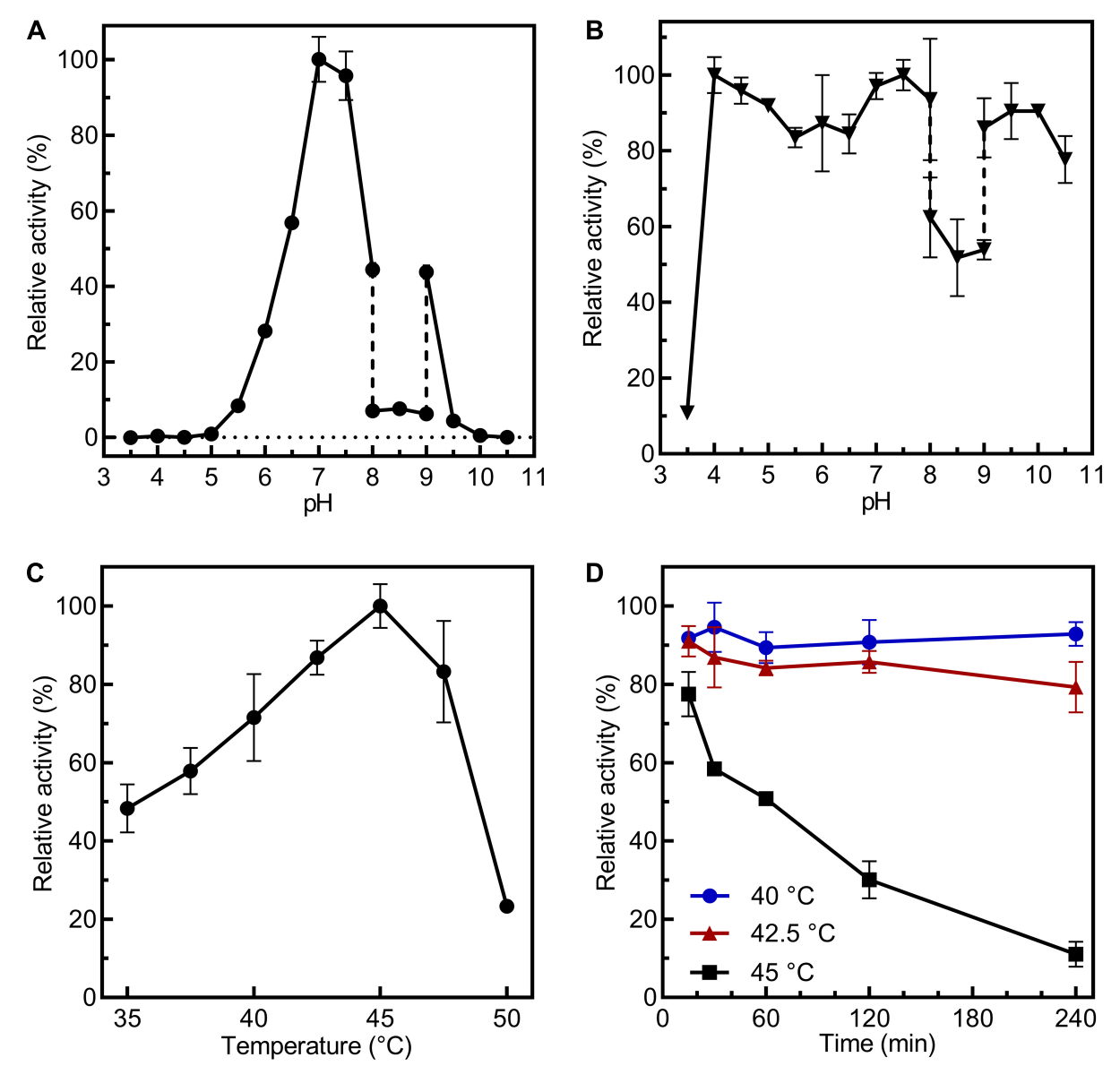

FIGURE 2 | Biochemical characterization of CsBGL. (A) Measurements of optimum pH of CsBGL. Reactions were performed at $45^{\circ} \mathrm{C}$ for 5 min at various pH values from 3.5 to 10.5 using pNP- $\beta$-Glc as substrate. (B) Measurements of pH stability of CsBGL. The CsBGL was incubated in the presence of various $p H$ values from 3.5 to 10.5 at $4^{\circ} \mathrm{C}$ for $24 \mathrm{~h}$ and measuring the residual activity. (C) Measurement of optimum temperature of CsBGL. Reactions were performed in $100 \mathrm{mM}$ sodium hydrogen phosphate-citric acid buffer ( $\mathrm{pH} 7.0)$ with $\mathrm{pNP}-\beta$-Glc at gradient temperatures from 30 to $50^{\circ} \mathrm{C}\left(2.5^{\circ} \mathrm{C}\right.$ intervals) for 5 min. (D) Measurement of temperature stability of CsBGL. The CsBGL was incubated at $40,42.5$, and $45^{\circ} \mathrm{C}$ for $15 \mathrm{~min}$ to $240 \mathrm{~min}$ and measuring its residual activity. All the experiments were carried out in triplicate.

approximately half of the activity was lost in an hour at $45^{\circ} \mathrm{C}$ (Figures $2 \mathrm{C}, \mathbf{D}) . \mathrm{Ag}^{+}$drastically inhibited the enzyme activity by $91 \% . \mathrm{K}^{+}, \mathrm{Li}^{+}, \mathrm{Hg}^{2+}, \mathrm{Cu}^{2+}, \mathrm{Cr}^{2+}, \mathrm{Mn}^{2+}$, and $\mathrm{Ca}^{2+}$ also impaired the activity by $6-34 \%$. By contrast, $\mathrm{Ni}^{2+}, \mathrm{Fe}^{2+}, \mathrm{Fe}^{3+}$, $\mathrm{Co}^{2+}$, and $\mathrm{Zn}^{2+}$ enhanced the activity of CsBGL by $8-28 \%$ (Supplementary Figure 5).

Using the $p \mathrm{NP}-\beta$-Glc as substrate, the initial reaction velocity of CsBGL was measured, and the $K_{m}, V_{\max }, k_{\text {cat }}, k_{\text {cat }} / K_{m}$, and $K_{i}$ (glucose) values were $1.62 \mathrm{mM}, 11.45 \mu \mathrm{M} \cdot \mathrm{min}^{-1} \cdot \mathrm{mg}^{-1}$ protein, $16.77 \mathrm{~s}^{-1}, 10.35 \mathrm{~s}^{-1} \cdot \mathrm{mM}^{-1}$, and $16.36 \mathrm{mM}$, respectively (Supplementary Figure 6).

\section{Determination of the Substrate Specificity of CsBGL for Hydrolysis}

To determine the glucosidic linkage specificity of CsBGL, 23 glucosides, including $\alpha / \beta$-glucosyl-linkage di-/tri-saccharides, natural products, and some steviol glycosides, were used to measure its catalytic activity (Figure 3). CsBGL showed the highest activity to RD with the C-13-linked Glc $\beta 1-2[\mathrm{Glc} \beta 1-3] \mathrm{Glc}$ trisaccharide and the C-19-linked Glc $\beta 1-2$ Glc disaccharide (sophorese). Compared with the hydrolysis of $\mathrm{RD}, \mathrm{Cs} B \mathrm{BL}$ displayed the relative activities ranging from 60.10 to $81.34 \%$ to stevioside (69.2\%) with C-13-linked Glc $\beta 1-2$ Glc disaccharide (sophorese) and the C-19-linked Glc $\beta 1$-monosaccharide, steviolbioside (60.1\%) with C-13-linked Glc $\beta 1$-2Glc disaccharide (sophorese) and the C-19-linked hydroxy group, sophorose (81.3\%, Glc $\beta 1-2 \mathrm{Glc})$ and laminaribiose (80.5\%, Glc $\beta 1-3 \mathrm{Glc})$. By contrast, the hydrolysis activity of CsBGL to cellobiose (Glc $\beta 1-4 \mathrm{Glc})$, gentiobiose (Glc $\beta 1-6 \mathrm{Glc})$, maltose (Glc $\alpha 1-4 \mathrm{Glc})$, lactose $(\mathrm{Gal} \beta 1-4 \mathrm{Glc})$, and esculoside (Glc $\beta$-aglycon) was poor with relative activities of $\sim 0.1 \%$ or lower than $0.1 \%$. Notably, CsBGL could not hydrolyze rubusoside with the C-13 or/and C19-linked Glc $\beta 1$-monosaccharides, steviolmonoside with the C-13-linked Glc $\beta 1$ - monosaccharide, and the C-19-linked hydroxy group, RA with the C-13-linked Glc $\beta 1-2[$ Glc $\beta 1-3]$ Glc trisaccharide and the C-19-linked Glc $\beta 1$-monosaccharide, RB with the C-13-linked Glc $\beta 1-2[$ Glc $\beta 1-3]$ Glc trisaccharide and 


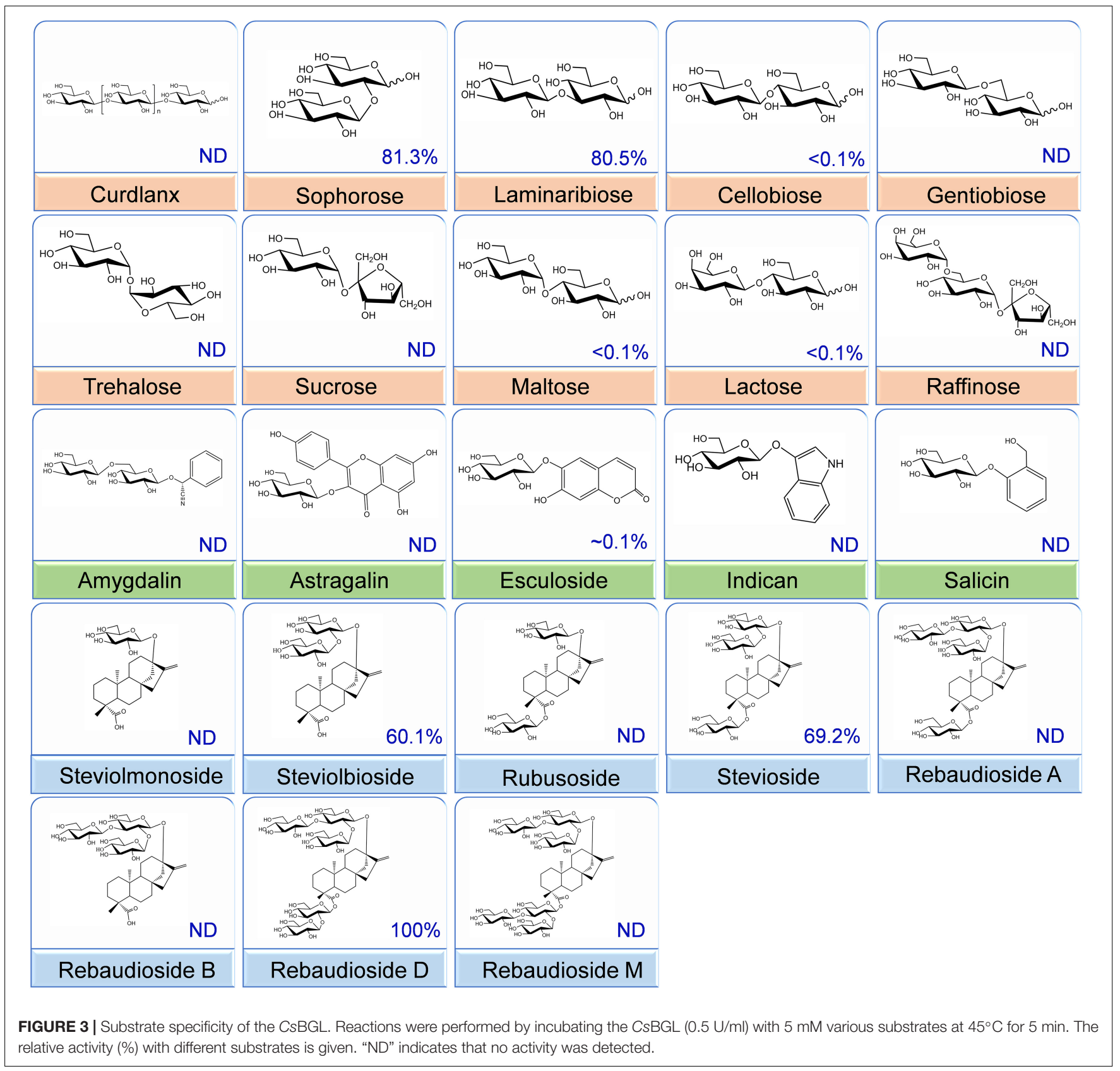

the C-19-linked hydroxy group, RM with the C-13 and C19linked Glc $\beta 1-2$ [Glc $\beta 1-3]$ Glc trisaccharides, curdlan (Glc $\beta 1-3 \mathrm{Glc}$ glucans), sucrose (Glc $\alpha 1-2 \beta \mathrm{Fru})$, trehalose (Glc $\alpha 1-1 \alpha \mathrm{Glc}$ ), raffinose (Gal $\alpha 1-6 \mathrm{Glc} \alpha 1-2 \beta \mathrm{Fru})$, astragalin (Glc $\beta$-aglycon), amygdalin (Glc $\beta 1-6 \mathrm{Glc} \beta$-aglycon), indican (Glc $\beta$-aglycon), and salicin (Glc $\beta$-aglycon).

Next, we employed HPLC (Figure 4) and ESI-MS (Supplementary Figure 7) to determine the hydrolysis products of different steviol glucosides by CsBGL. RD was hydrolyzed to RA with the retention time at $6.2 \mathrm{~min}$ in HPLC and the peak of $[\mathrm{M}-\mathrm{H}]^{-}$ion at $m / z 965.41$, consistent with the molecular mass of RA (966.43). Stevioside was hydrolyzed to rubusoside with the retention time at $11.2 \mathrm{~min}$ in HPLC and the peak of $[\mathrm{M}-\mathrm{H}]^{-}$ion at $m / z 641.32$, consistent with the molecular mass of rubusoside (642.32). Steviolbioside was hydrolyzed to steviolmonoside with the retention time at $15.6 \mathrm{~min}$ in HPLC and the peak of [M-H] ${ }^{-}$ion at $m / z 479.26$, consistent with the molecular mass of steviolmonoside (480.27). Notably, the results of HPLC also showed that RM, RA, RB, rubusoside, and steviolmonoside were not hydrolyzed, which agreed with the biochemical measurements. Collectively, these results suggested that when steviol glucosides were used as substrates, CsBGL specifically cleaved the $\mathrm{C}$-13 or $\mathrm{C}$-19-linked $\beta$-1,2-glucosidic linkage in sophorosyl disaccharide, whereas it could not hydrolyze a single $\beta$-D-glucopyranosyl unit and the Glc $\beta 1-2[\mathrm{Glc} \beta 1-3] \mathrm{Glc}$ trisaccharide moiety. 


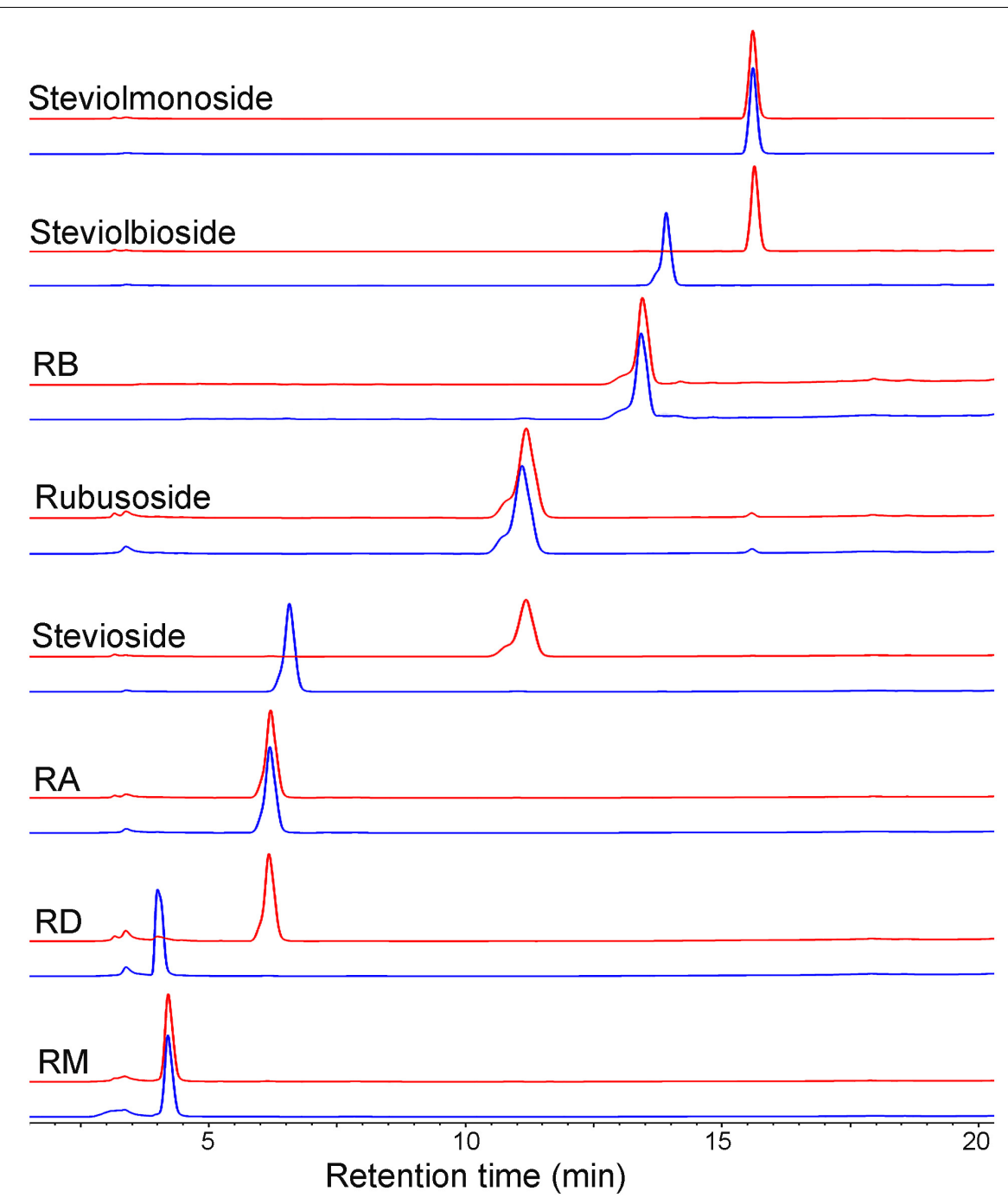

FIGURE 4 | HPLC analysis of the hydrolysis products of steviol glucosides by CsBGL. Reactions were performed by incubating CsBGL (0.5 U/ml) with 5 mM RM, $\mathrm{RD}, \mathrm{RA}$, stevioside, rubusoside, RB, steviolbioside, and steviolmonoside in the $50 \mathrm{mM}$ sodium phosphate buffer (pH 7.4 ) at $45^{\circ} \mathrm{C}$ for 5 min. The red lines represent the hydrolysis product of steviol glycosides by CsBGL and the blue lines represent the control of steviol glycosides.

\section{The Mass Production of Rubusoside From Stevioside}

The reactions for production of rubusoside were performed by incubating CsBGL $(600 \mu \mathrm{g} / \mathrm{ml}, 30.9 \mathrm{U} / \mathrm{ml})$ with stevioside $(240 \mathrm{~g} / \mathrm{L})$. The $\mathrm{pH}$ value strongly affected the rubusoside yield at $45^{\circ} \mathrm{C}$ for $40 \mathrm{~min}$. As showed in Figure $\mathbf{5 A}$, the rubusoside yield increased from $40.4 \%$ at $\mathrm{pH} 5.0$ to $78.5 \%$ at $\mathrm{pH} 6.5$ and then decreased to $10.1 \%$ at $\mathrm{pH} 10.0$. The reaction temperature also markedly affected the hydrolysis of stevioside at $\mathrm{pH} 6.5$ for $40 \mathrm{~min}$. When the temperature increased from 35 to $47.5^{\circ} \mathrm{C}$, the rubusoside yield increased from $32.6 \%$ at $35^{\circ} \mathrm{C}$ to the maximum yield of $85.7 \%$ at $47.5^{\circ} \mathrm{C}$, then the yield slightly decreased to $83.8 \%$ at $50^{\circ} \mathrm{C}$ (Figure $5 \mathbf{B}$ ). The time course of the reaction at $47.5^{\circ} \mathrm{C}$ and $\mathrm{pH} 6.5$ showed that the highest stevioside conversion of $99 \%$ and the rubusoside yield of $99 \%$ were achieved at 70 min (Figure 5C).
The initial reaction velocity of CsBGL for the hydrolysis of stevioside was also determined in $50 \mathrm{mM}$ sodium phosphate buffer ( $\mathrm{pH} 6.5$ ) at $47.5^{\circ} \mathrm{C}$. The $K_{m}, V_{\text {max }}, k_{\text {cat }}$, and $k_{\text {cat }} / K_{m}$ values were $1.54 \mathrm{mM}, 169.70 \mu \mathrm{M} \cdot \mathrm{min}^{-1} \cdot \mathrm{mg}^{-1}$ protein, $248.59 \mathrm{~s}^{-1}$, and $160.49 \mathrm{~s}^{-1} \cdot \mathrm{mM}^{-1}$, respectively (Supplementary Figure 8).

Moreover, using the crude steviol glycosides extract as the substrate, we carried out the rubusoside production by CsBGL; $500 \mathrm{~g} / \mathrm{L}$ crude steviol glycosides extract containing $\sim 226 \mathrm{~g} / \mathrm{L}$ of stevioside (calculated by the peak area of HPLC) and $300 \mu \mathrm{g} / \mathrm{ml}$ (15.5 U/ml) CsBGL was used in the reaction. The HPLC results revealed that almost all stevioside in the crude steviol glycosides extract was hydrolyzed and converted to rubusoside (P1, Figure 6) at $47.5^{\circ} \mathrm{C}$ for $2 \mathrm{~h}$. The rubusoside concentration was increased from the initial $42 \mathrm{~g} / \mathrm{L}$ in the crude steviol glycosides extract to $222 \mathrm{~g} / \mathrm{L}$ in the final reaction solution. At the same time, it was found that RD with the Glc $\beta 1-2 \mathrm{Glc}$ sophorese 

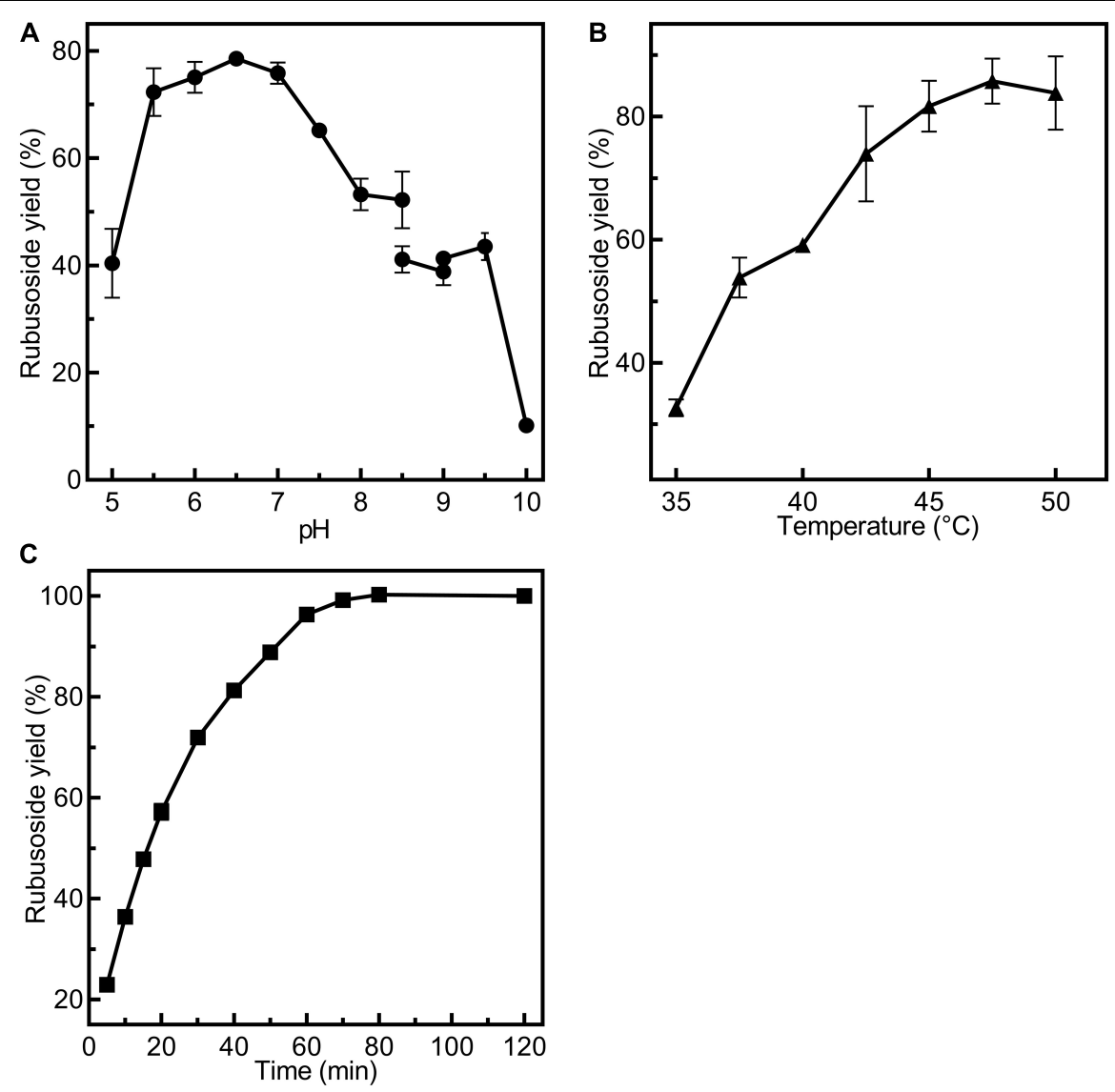

FIGURE 5 | Condition exploration for production of rubusoside using $30.9 \mathrm{U} / \mathrm{ml} \mathrm{CsBGL}$ and $240 \mathrm{~g} / \mathrm{L}$ stevioside. (A) Effects of pH on the rubusoside yield. Reactions were performed at $45^{\circ} \mathrm{C}$ for $40 \mathrm{~min}$ at various $\mathrm{pH}$ values from 5 to 10. (B) Effects of temperature on the rubusoside yield. Reactions were performed in $50 \mathrm{mM}$ sodium phosphate buffer ( $\mathrm{pH}$ 6.5) for $40 \mathrm{~min}$ at several different temperatures ranging from 35 to $50^{\circ} \mathrm{C}$ with $2.5^{\circ} \mathrm{C}$ intervals. (C) The time course of rubusoside yield from 5 to $120 \mathrm{~min}$. Reactions were performed in $1 \mathrm{ml} 50 \mathrm{mM}$ sodium phosphate buffer $\left(\mathrm{pH}\right.$ 6.5) at $47.5^{\circ} \mathrm{C}$ for 5 to $120 \mathrm{~min}$. A $50 \mu \mathrm{l}$ sample was taken out with 5-10-min intervals. All the experiments were carried out in triplicate.

at the C-19 site and steviolbioside with the Glc $\beta 1-2 \mathrm{Glc}$ sophorese at the $\mathrm{C}-13$ site were hydrolyzed to RA and steviomonoside, respectively, and another major steviol glycoside RA with a single $\beta$-D-glucopyranosyl unit at the C-19 site and the Glc $\beta 1-2[$ Glc $\beta 1$ 3] Glc trisaccharide moiety at the C-13-site were not hydrolyzed in the reaction.

\section{Isolation and Identification of Rubusoside}

The hydrolysis product from stevioside by CsBGL was separated by Bio-Gel P2 and its chemical structure was identified. In the HPLC analysis, the retention time $(11.2 \mathrm{~min})$ of the hydrolysis product was consistent with rubusoside control (Figure 4). The negative-ion ESI-MS analysis of the hydrolysis product showed peaks of $[\mathrm{M}-\mathrm{H}]^{-}$ion at $m / z$ 641.32, $\left[\mathrm{M}+\mathrm{HCOO}^{-}\right.$ion at $m / z 687.32$ and $\left[\mathrm{M}+\mathrm{CF}_{3} \mathrm{COO}\right]^{-}$ion at $\mathrm{m} / z$ 755.31; consistent with the molecular mass of rubusoside (642.33), the peak of [M-Glc-H] $]^{-}$ion at $\mathrm{m} / z 479.26$ was consistent with a fragment (480.27) of rubusoside, due to the breakdown at the glucose ester bond at the C-19 site (Supplementary Figure 7B). The alkaline hydrolysis analysis showed that the hydrolysis product contained a glucopyranosyl unit at the C-19 site, same as the rubusoside (Supplementary Figure 9). Furthermore, NMR spectrum further confirmed that the hydrolysis product from stevioside by CsBGL was rubusoside. In the full ${ }^{1} \mathrm{H}$ NMR spectrum (Figure 7A), four peaks, including $\delta 5.25\left(\mathrm{~d}, J=8.1 \mathrm{~Hz},{ }^{1} \mathrm{H}\right), \delta 5.08\left(\mathrm{~s},{ }^{1} \mathrm{H}\right), \delta$ $4.74\left(\mathrm{~s},{ }^{1} \mathrm{H}\right)$, and $4.28\left(\mathrm{~d}, J=7.8 \mathrm{~Hz},{ }^{1} \mathrm{H}\right)$ were detected in the anomeric region (4.2-5.3 ppm) which were labeled as a1, b1, b2, and a2 from low to high field, respectively. The high $J$ coupling distances for peaks a $1(8.1 \mathrm{~Hz})$ and a2 $(7.8 \mathrm{~Hz})$ suggested that glucose residues of a1 and a 2 adopted a $\beta$-configuration, while peaks b1 and b2 were single peaks and showed that they were not anomeric proton signals and resolved as the proton signals linked to olefin (C-17) of aglycon. In the ${ }^{13} \mathrm{C}$ NMR spectrum, because of the carboxyl group $(\mathrm{C}-19)$ and $\mathrm{C}=\mathrm{C}$ double bonds (C-16 and C-17), three peaks were observed at downfield (C-19, 175.92 ppm; C-16, 153.23 ppm; and C-17, $104.39 \mathrm{ppm}$ ) (Supplementary Figure 10). The anomeric proton and carbon of the sugar units were assigned by the ${ }^{1} \mathrm{H}-{ }^{1} \mathrm{H}$ COSY, HSQC, HMBC, and TOCSY (Supplementary Figures 11-13 and Figure 7B). From the HMBC, a cross peak between $\mathrm{H}-1$ of 


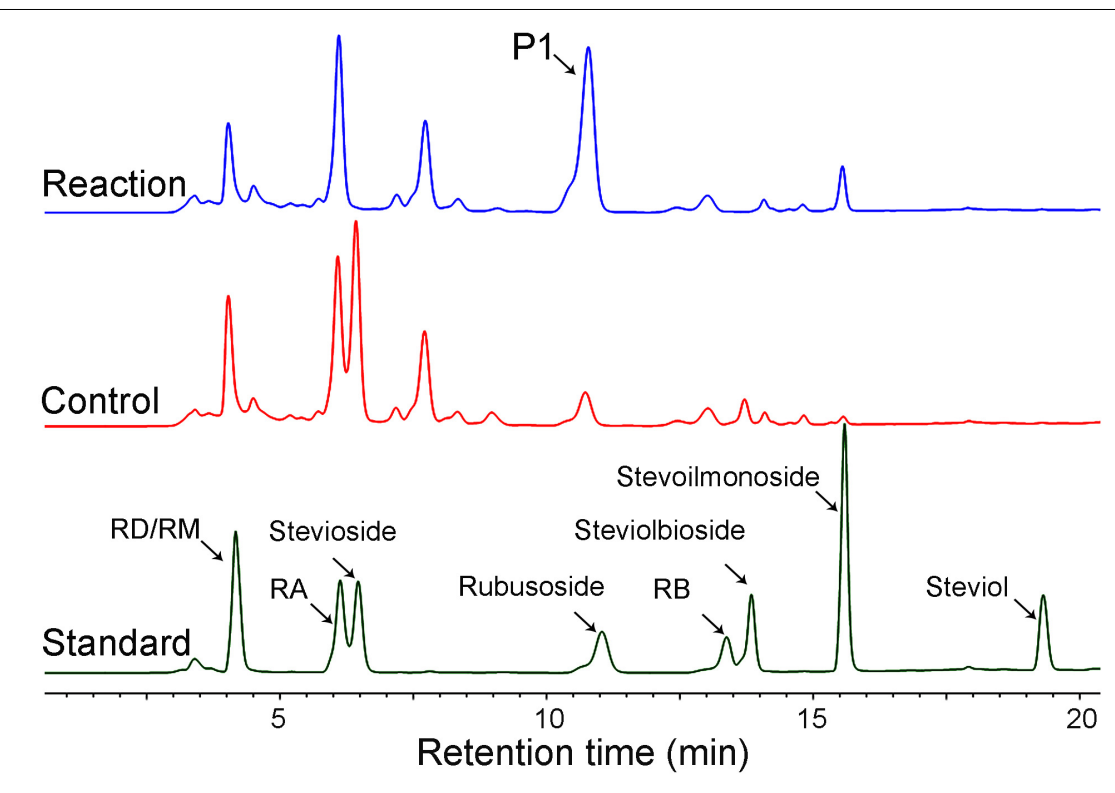

FIGURE 6 | HPLC analysis of the hydrolysis products of crude steviol glycosides extract (500 g/L) by CsBGL. Reactions (blue line) were performed by incubating CsBGL $\left(15.5 \mathrm{U} / \mathrm{ml}\right.$ ) with crude steviol glycosides extract in $50 \mathrm{mM}$ sodium phosphate buffer ( $\mathrm{pH}$ 6.5) at $47.5^{\circ} \mathrm{C}$ for $2 \mathrm{~h}$. P1 indicates rubusoside. The control (red line) was performed by inactive enzyme under the same condition, with the same reactions. The standard substrates are shown in dark green line.

glucose I ( $\delta 5.25 \mathrm{ppm})$ and C-19 of aglycon ( $\delta 175.92 \mathrm{ppm})$ was clearly found (Figure 7B), indicating that the glucose I was linked on the C-19 of aglycon. A cross peak between $\mathrm{H}-1$ of glucose II ( $\delta$ $4.28 \mathrm{ppm}$ ) and C-13 of aglycon ( $\delta 85.19 \mathrm{ppm})$ was clearly found (Figure 7B), indicating that the glucose II was linked to the C-13 of aglycon. Moreover, the complete NMR data are characterized in the Supplementary Material and the chemical shifts of proton and carbon signals of rubusoside are listed in Supplementary Table 1. Accordingly, the chemical structure of the hydrolysis product from stevioside by CsBGL was rubusoside. The NMR spectrum of rubusoside was consisted in the works reported by Guo et al. (2019) and Wang et al. (2021). The process of CsBGL conversion of stevioside into rubusoside is shown in Figure 8.

\section{DISCUSSION}

As an environment-friendly strategy to produce bioactive compounds, glycosidases have been widely used to convert steviol glycosides to produce steviol, steviolmonoside, steviolbioside, rubusoside, and other minor components of steviol glycosides (Nakano et al., 1998; Ko et al., 2013; Chen et al., 2014, 2016; Udompaisarn et al., 2017; Lan et al., 2019). In the present study, we identified a novel $\beta$-glucosidase, CsBGL, which showed excellent efficient and specific hydrolysis activity to produce rubusoside from stevioside.

CsBGL showed strict hydrolytic specificity to the $\beta-1$, 2-glucosidic bond in the sophorosyl disaccharide without $\beta$ 1,3-glucosidic bond branch and did not hydrolyze the single $\beta$-D-glucopyranosyl unit in steviol glycosides. This strict substrate specificity of CsBGL was speculated to be related to the characteristic $3 \mathrm{D}$ structures modeling of the enzyme.
The docking model of CsBGL with the stevioside as the ligand showed that the sophorosyl disaccharide of stevioside was nestled in the catalytic cavity of CsBGL formed by four aromatic residues (F71, Y278, F245, and W416). The Glc $\beta 1$ 2 [Glc $\beta 1-3]$ Glc trisaccharide moiety could not get in this narrow catalytic cavity. For the single $\beta$-D-glucopyranosyl unit in steviol glycosides, the W416 and H463 blocked the aglycon of steviol glycosides, probably resulting that the single $\beta$-Dglucopyranosyl unit could not get to the appropriate site of catalytic cavity. These results could account for the strict substrate specificity of CsBGL that strongly hydrolyzed stevioside but not rubusoside.

In 2012, it was reported that SSGase (a Sigma-Aldrich's commercial enzyme) could hydrolyze both stevioside and rubusoside, but its hydrolysis activity to rubusoside was low, only about $29.0 \%$ of that to stevioside. When the enzyme activity of SSGase was measured with stevioside and rubusoside as substrates, the enzyme activity for stevioside was $14.5 \mathrm{U}$, while that for rubusoside was $4.2 \mathrm{U}$. For the rubusoside production from the hydrolysis of stevioside, SSGase could hydrolyze stevioside $(280 \mathrm{mM})$ to produce rubusoside $(193 \mathrm{mM})$ at $63^{\circ} \mathrm{C}$ for 7 days, which indicated the rubusoside produced in the reaction solution could be accumulated to a certain extent, but the slow hydrolysis of rubusoside by SSGase could cause its concentration to be lower than that of hydrolyzed stevioside (Ko et al., 2012). In 2015, it was reported that the BGL1 from Streptomyces sp. GXT6 CGMCC 7091 hydrolyzed stevioside $(10 \mathrm{~g} / \mathrm{L})$ to produce rubusoside at $50^{\circ} \mathrm{C}$ for $6 \mathrm{~h}$ with the stevioside conversion rate of $98.2 \%$ and the rubusoside yield of $78.8 \%$ (w/w) (Wang et al., 2015). As reported in 2019, the SPBGL1 from S. elodea ATCC 31461 selectively hydrolyzed purified stevioside $(240 \mathrm{~g} / \mathrm{L})$ or crude steviol glycosides extract $(500 \mathrm{~g} / \mathrm{L})$ to produce rubusoside 


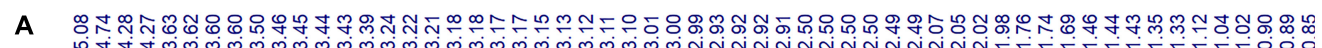

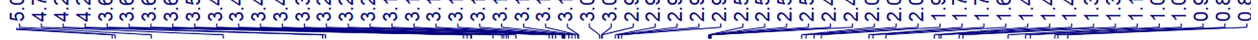
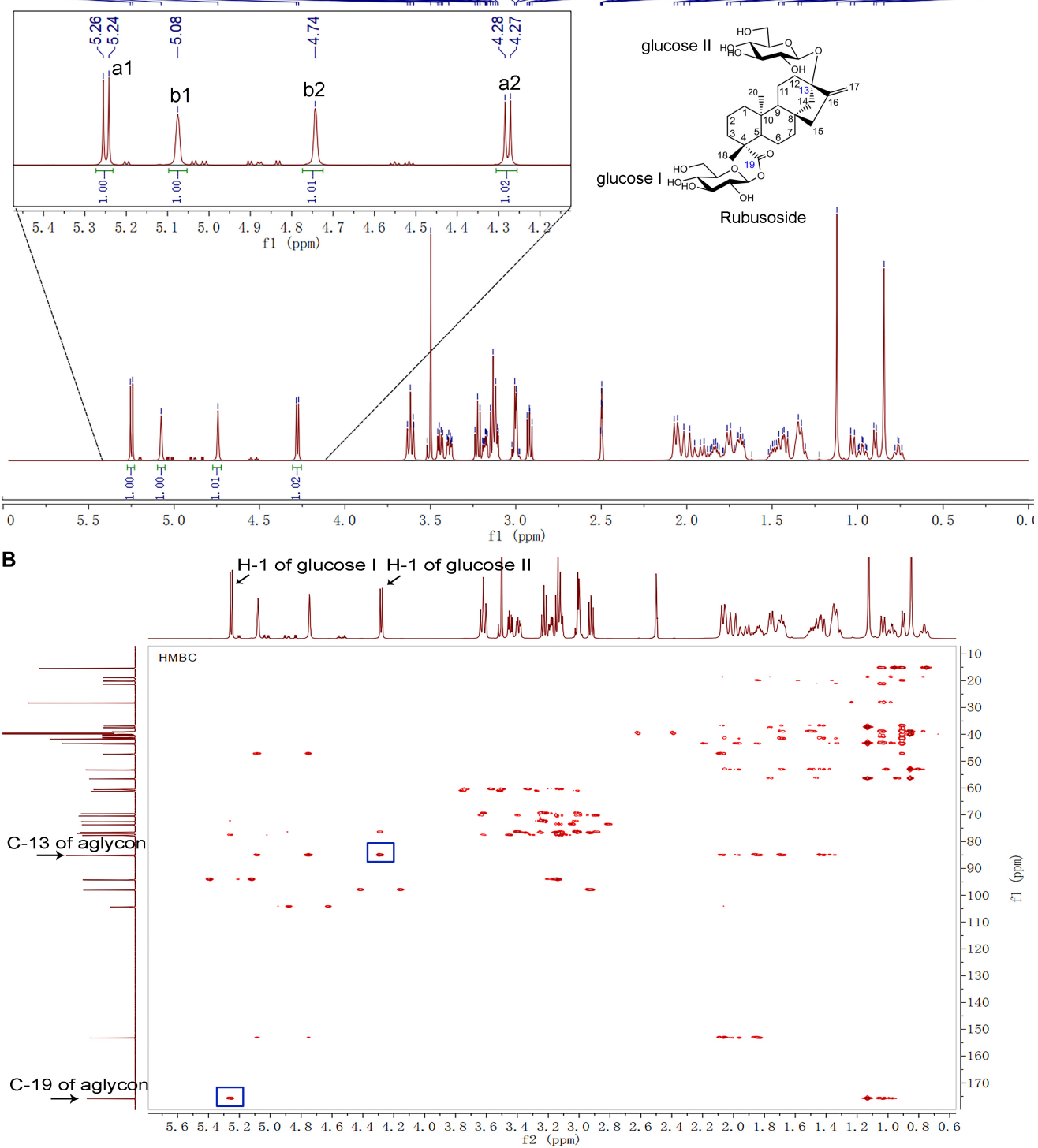

FIGURE 7 | NMR analysis of the hydrolysis production from stevioside by CsBGL. ( $\delta$ : ppm) (A) ${ }^{1} \mathrm{H}-\mathrm{NMR} 600 \mathrm{MHz}$ spectrum. The four peaks in the anomeric region (4.2-5.3 ppm) were labeled as a1, b1, b2, and a2, from low to high field. (B) HMBC NMR spectrum. The H-1 of glucose l/ll, C-13/19 of aglycon, and their cross peaks were labeled.

at $45^{\circ} \mathrm{C}$ for $6 \mathrm{~h}$ with the stevioside conversion rate of $98.6 \%$ and rubusoside yield of $99 \%$ using $600 \mu \mathrm{g} / \mathrm{ml}$ of enzyme (Lan et al., 2019). In the same year, the EcBgl from E. casseliflavus strain EC20 was also reported to convert stevioside to rubusoside but the stevioside conversion rate and rubusoside yield were not shown (Boonkaew et al., 2019). It is obvious from the above description that the reactions catalyzed by SSGase, BGL1, and SPBGL1 all took a long time ( $\geq 6 \mathrm{~h}$ ). In the present study, a novel $\beta$-glucosidase (CsBGL) was found to have much better catalytic properties. When purified stevioside $(240 \mathrm{~g} / \mathrm{L})$ was used as the substrate in the reaction, CsBGL selectively hydrolyzed stevioside to produce rubusoside at $47.5^{\circ} \mathrm{C}$ for $70 \mathrm{~min}$ with stevioside conversion rate of $99 \%$ and rubusoside yield of $99 \%$ using
$600 \mu \mathrm{g} / \mathrm{ml}(30.9 \mathrm{U} / \mathrm{ml})$ of enzyme. When crude steviol glycosides extract (500 g/L containing stevioside $\sim 226 \mathrm{~g} / \mathrm{L}$ ) were used as the substrate in the reaction, CsBGL selectively hydrolyzed stevioside, $\mathrm{RD}$, and steviolbioside to produce rubusoside, $\mathrm{RA}$, and steviolmonoside, respectively, at $47.5^{\circ} \mathrm{C}$ for $2 \mathrm{~h}$ with rubusoside yield of $\sim 99 \%$, using $300 \mu \mathrm{g} / \mathrm{ml}(15.5 \mathrm{U} / \mathrm{ml})$ of enzyme. To the best of our knowledge, this is the most efficient enzyme for producing the rubusoside from stevioside. Compared with SPBGL1 from S. elodea ATCC 31461 that needs $6 \mathrm{~h}$ to catalyze the hydrolysis of purified stevioside $(240 \mathrm{~g} / \mathrm{L})$ or crude steviol glycosides extract $(500 \mathrm{~g} / \mathrm{L})$, the reaction time of CsBGL was shortened by about $4.8-4 \mathrm{~h}$ with almost the same stevioside conversion and rubusoside yield. The $K_{m}, k_{\mathrm{cat}}$, and $k_{\mathrm{cat}} / K_{m}$ values 


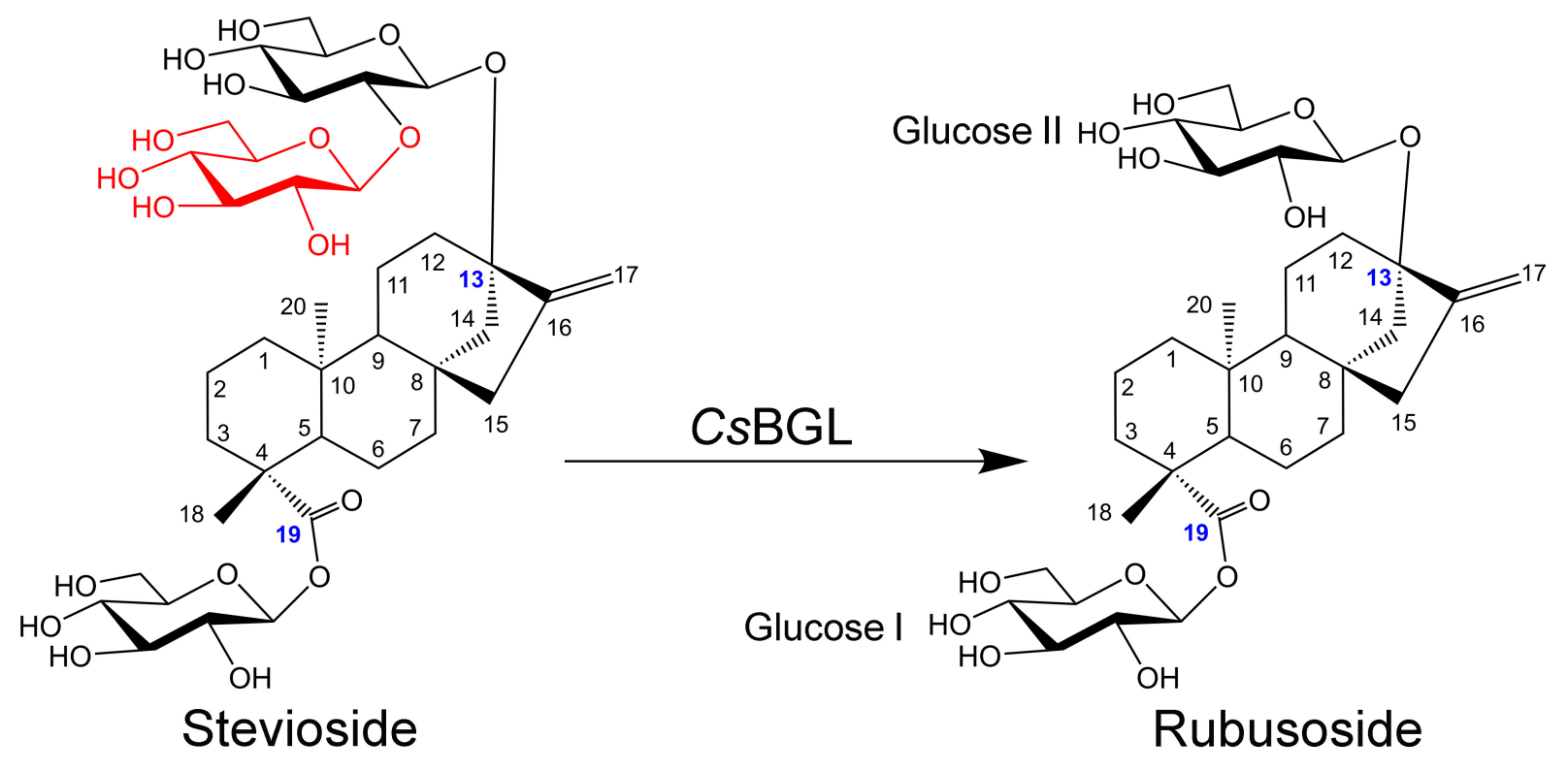

FIGURE $\mathbf{8}$ | Schematic diagram of production of rubusoside from the hydrolysis of stevioside catalyzed by CsBGL. The blue numbers label the carbon atoms that link with the sugar groups, the different structural moiety between stevioside and rubusoside is displayed in red.

toward stevioside of CsBGL were compared with four other reported $\beta$-glucosidases, in particular (Table 1). CsBGL displayed the lowest $K_{m}$ value of $1.5 \mathrm{mM}$ among the enzymes, which means it had the strongest substrate-binding affinity. Furthermore, the $k_{\text {cat }} / K_{m}$ value of CsBGL $\left(160.5 \mathrm{~s}^{-1} \cdot \mathrm{mM}^{-1}\right)$ was approximately 1.7 and 4.1 times higher than that of the $\operatorname{EcBgl}\left(95.38 \mathrm{~s}^{-1} \cdot \mathrm{mM}^{-1}\right)$ and SPBGL1 $\left(39.1 \mathrm{~s}^{-1} \cdot \mathrm{mM}^{-1}\right)$, respectively, which highlighted its better catalytic performance.

A crude hesperidinase from Aspergillus niger (Mizukami et al., 1981 ) and a $\beta$-glucosidase BT_3567 from $B$. thetaiotaomicron HB13 (Udompaisarn et al., 2017) were used to determine stevioside in Stevia samples based on the hydrolysis reaction to release glucose. However, both enzymes could non-specifically hydrolyze RA, which is usually another major component of steviol glycosides, and thereby, the glucose produced by the hydrolysis of RA would affect the accuracy of the determination. Interestingly, CsBGL could specifically cleave the $\beta$-1,2-glucosidic linkage in sophorosyl disaccharide of stevioside to produce equimolar glucose without hydrolyzing RA in the crude steviol glycosides extract, which might be developed as a high-throughput method to precisely quantify the stevioside content in Stevia samples.

TABLE 1 | Kinetic parameters toward stevioside of reported $\beta$-glucosidase.

\begin{tabular}{lcccl}
\hline $\boldsymbol{\beta}$-Glucosidase & $\begin{array}{c}\boldsymbol{K}_{\boldsymbol{m}} \\
(\mathbf{m M})\end{array}$ & $\begin{array}{c}\boldsymbol{k}_{\text {cat }} \\
\left(\mathbf{s}^{-\mathbf{1}}\right)\end{array}$ & $\begin{array}{c}\boldsymbol{k}_{\text {cat }} / \boldsymbol{K}_{\boldsymbol{m}} \\
\mathbf{( s}^{-\mathbf{1}} \mathbf{m} \mathbf{M}^{-\mathbf{1}} \mathbf{)}\end{array}$ & References \\
\hline CsBGL & 1.5 & 248.6 & 160.5 & This study \\
BGL1 & 1.5 & 13.2 & 9.0 & Wang et al., 2015 \\
SPBGL1 & 3.1 & 121.3 & 39.1 & Lan et al., 2019 \\
SSGase & 3.6 & 30.4 & 8.5 & Ko et al., 2012 \\
EcBgl & 1.820 & 173.60 & 95.38 & Boonkaew et al., 2019
\end{tabular}

\section{CONCLUSION}

A novel $\beta$-glucosidase CsBGL obtained here could markedly hydrolyze sophorese (Glc $\beta 1-2 \mathrm{Glc})$, laminaribiose (Glc $\beta 1-3 \mathrm{Glc}$ ), and the C-13- or/and C-19-linked sophorese of steviol glycosides, but not the C-13 or/and C-19-linked Glc $\beta 1-2[\mathrm{Glc} \beta 1-3] \mathrm{Glc}$ trisaccharide and Glc $\beta 1$-monosaccharide of steviol glycosides. The enzyme could efficiently convert the high concentration stevioside $(240 \mathrm{~g} / \mathrm{L})$ at $47.5^{\circ} \mathrm{C}$ for $70 \mathrm{~min}$ and crude steviol glycosides extract $(500 \mathrm{~g} / \mathrm{L})$ containing $\sim 226 \mathrm{~g} / \mathrm{L}$ stevioside at $47.5^{\circ} \mathrm{C}$ for $2 \mathrm{~h}$ to produce rubusoside with the stevioside conversion of $99 \%$ and rubusoside yield of $99 \%$. To the best of our knowledge, CsBGL is the most efficient enzyme for the biological production of rubusoside from stevioside and has a potential in industrial applications.

\section{DATA AVAILABILITY STATEMENT}

The datasets presented in this study can be found in online repositories. The names of the repository/repositories and accession number(s) can be found below: https://www.ncbi. nlm.nih.gov/genbank/, https://www.ncbi.nlm.nih.gov/genbank/, https://www.ncbi.nlm.nih.gov/genbank/.

\section{AUTHOR CONTRIBUTIONS}

ZY designed the research, collected the samples, performed the experiments, analyzed the data, and wrote the manuscript. XC, XY, and SY performed part of the experiments. LX, XJ, and MX supervised the project, analyzed the data, and revised the 
manuscript. All authors contributed to the article and approved the submitted version.

\section{FUNDING}

This work was partly supported by the National Key Research and Development Program of China (2018YFA0902000), National Natural Science Foundation of China (31872626), and Central Government Guide Local Science and Technology Development Funds (YDZX20203700002579). XJ was supported by the Fundamental Research Funds of Shandong University.

\section{REFERENCES}

Bankevich, A., Nurk, S., Antipov, D., Gurevich, A. A., Dvorkin, M., Kulikov, A. S., et al. (2012). SPAdes: a new genome assembly algorithm and its applications to single-cell sequencing. J. Comput. Biol. 19, 455-477. doi: 10.1089/cmb.2012. 0021

Boetzer, M., and Pirovano, W. (2012). Toward almost closed genomes with GapFiller. Genome Biol. 13:R56. doi: 10.1186/gb-2012-13-6-r56

Boonkaew, B., Udompaisarn, S., Arthan, D., and Somana, J. (2019). Expression and characterization of a recombinant stevioside hydrolyzing beta-glycosidase from Enterococcus casseliflavus. Protein Expr. Purif. 163:105449. doi: 10.1016/j.pep. 2019.105449

Brunelle, J. L., and Green, R. (2014). One-dimensional SDS-polyacrylamide gel electrophoresis (1D SDS-PAGE). Methods Enzymol. 541, 151-159. doi: 10.1016/ B978-0-12-420119-4.00012-4

Chen, J. M., Ding, L., Sui, X. C., Xia, Y. M., Wan, H. D., and Lu, T. (2016). Production of a bioactive sweetener steviolbioside via specific hydrolyzing ester linkage of stevioside with a beta-galactosidase. Food Chem. 196, 155-160. doi: 10.1016/j.foodchem.2015.09.035

Chen, J.-M., Xia, Y.-M., Wan, H.-D., Wang, H.-J., and Liu, X. (2014). A complete specific cleavage of glucosyl and ester linkages of stevioside for preparing steviol with a $\beta$-galactosidase from Sulfolobus solfataricus. J. Mol. Catal. B Enzymat. 105, 126-131. doi: 10.1016/j.molcatb.2014.03.011

Chou, G., Xu, S. J., Liu, D., Koh, G. Y., Zhang, J., and Liu, Z. (2009). Quantitative and fingerprint analyses of Chinese sweet tea plant (Rubus suavissimus S. Lee). J. Agric. Food Chem. 57, 1076-1083. doi: 10.1021/jf8029397

Darise, M., Mizutani, K., Kasai, R., Tanaka, O., Kitahata, S., Okada, S., et al. (1984). Enzymic transglucosylation of rubusoside and the structure-sweetness relationship of steviol-bisglycosides. Agric. Biol. Chem. 48, 2483-2488. doi: 10.1080/00021369.1984.10866520

Edberg, S. C., Gam, K., Bottenbley, C. J., and Singer, J. M. (1976). Rapid test for determination of esculin hydrolysis. J. Clin. Microbiol. 2, 180-184.

Gerwig, G. J., Te Poele, E. M., Dijkhuizen, L., and Kamerling, J. P. (2016). Stevia glycosides: chemical and enzymatic modifications of their carbohydrate moieties to improve the sweet-tasting quality. Adv. Carbohydr. Chem. Biochem. 73, 1-72. doi: 10.1016/bs.accb.2016.05.001

Guo, Q., Zhang, T., Wang, N., Xia, Y., Zhou, Z., Wang, J. R., et al. (2019). RQ3, a natural rebaudioside $\mathrm{d}$ isomer, was obtained from glucosylation of rebaudioside a catalyzed by the CGTase Toruzyme 3.0 L. J. Agric. Food Chem. 67, 8020-8028. doi: 10.1021/acs.jafc.9b02545

Ishiguro, R., Tanaka, N., Abe, K., Nakajima, M., Maeda, T., Miyanaga, A., et al. (2017). Function and structure relationships of a beta-1,2glucooligosaccharide-degrading beta-glucosidase. FEBS Lett. 591, 3926-3936. doi: 10.1002/1873-3468.12911

Jin-ao, D., Rui, L., Da-wei, Q., and Zhen-hua, Z. (2017). Analysis and identification of proteins and peptides from goat horn (Caprae Hircus Cornu) using nano LCLTQ/Orbitrap MS. J. Chinese Mass Spectrom. Soc. 38, 109-115. doi: 10.7538/ zpxb.2017.38.01.0109

Kim, J., Nguyen, T. T. H., Jin, J., Septiana, I., Son, G.-M., Lee, G.-H., et al. (2019). Anti-cariogenic characteristics of rubusoside. Biotechnol. Bioproc. E 24, 282-287. doi: 10.1007/s12257-018-0408-0

\section{ACKNOWLEDGMENTS}

We would like to thank Jingyao Qu, Jing Zhu, and Zhifeng Li from State Key Laboratory of Microbial Technology of Shandong University for help and guidance in peptide mapping analysis.

\section{SUPPLEMENTARY MATERIAL}

The Supplementary Material for this article can be found online at: https://www.frontiersin.org/articles/10.3389/fmicb. 2021.744914/full\#supplementary-material

Ko, J. A., Kim, Y. M., Ryu, Y. B., Jeong, H. J., Park, T. S., Park, S. J., et al. (2012). Mass production of rubusoside using a novel stevioside-specific betaglucosidase from Aspergillus aculeatus. J. Agric. Food Chem. 60, 6210-6216. doi: 10.1021/jf300531e

Ko, J. A., Ryu, Y. B., Kwon, H. J., Jeong, H. J., Park, S. J., Kim, C. Y., et al. (2013). Characterization of a novel steviol-producing beta-glucosidase from Penicillium decumbens and optimal production of the steviol. Appl. Microbiol. Biotechnol. 97, 8151-8161. doi: 10.1007/s00253-013-4883-0

Lan, Q., Tang, T., Yin, Y., Qu, X., Wang, Z., Pang, H., et al. (2019). Highly specific sophorose beta-glucosidase from Sphingomonas elodea ATCC 31461 for the efficient conversion of stevioside to rubusoside. Food Chem. 295, 563-568. doi: 10.1016/j.foodchem.2019.05.164

Liu, M., Li, X., Liu, Q., Xie, S., Chen, M., Wang, L., et al. (2020). Comprehensive profiling of $\alpha$-glucosidase inhibitors from the leaves of Rubus suavissimus using an off-line hyphenation of HSCCC, ultrafiltration HPLC-UV-MS and prep-HPLC. J. Food Compos. Anal. 85:103336. doi: 10.1016/j.jfca.2019.10 3336

Liu, Z., Schwimer, J., Liu, D., Lewis, J., Greenway, F. L., York, D. A., et al. (2006). Gallic acid is partially responsible for the antiangiogenic activities of Rubus leaf extract. Phytother. Res. 20, 806-813. doi: 10.1002/ptr.1966

McAndrew, R. P., Park, J. I., Heins, R. A., Reindl, W., Friedland, G. D., D'Haeseleer, P., et al. (2013). From soil to structure, a novel dimeric betaglucosidase belonging to glycoside hydrolase family 3 isolated from compost using metagenomic analysis. J. Biol. Chem. 288, 14985-14992. doi: 10.1074/jbc. M113.458356

Mizukami, H., Shiiba, K., and Ohashi, H. (1981). Enzymatic determination of stevioside in Stevia rebaudiana. Phytochemistry 21, 1927-1930.

Nakajima, M., Yoshida, R., Miyanaga, A., Abe, K., Takahashi, Y., Sugimoto, N., et al. (2016). Functional and structural analysis of a beta-glucosidase involved in beta-1,2-glucan metabolism in Listeria innocua. PLoS One 11:e0148870. doi: 10.1371/journal.pone.0148870

Nakano, H., Okamoto, K., Yatake, T., Kiso, T., and Kitahata, S. (1998). Purification and characterization of a novel $\beta$-glucosidase from Clavibacter michiganense that hydrolyzes glucosyl ester linkage in steviol glycosides. J. Ferm. Bioeng. 85, 162-168. doi: 10.1016/S0922-338X(97)86761-X

Nguyen, T. T., Jung, S. J., Kang, H. K., Kim, Y. M., Moon, Y. H., Kim, M., et al. (2014). Production of rubusoside from stevioside by using a thermostable lactase from Thermus thermophilus and solubility enhancement of liquiritin and teniposide. Enzym. Microb. Technol. 64-65, 38-43. doi: 10.1016/ j.enzmictec.2014.07.001

Pompeu, D. G., Mattioli, M. A., Ribeiro, R. I. M. D. A., GonÇAlves, D. B., MagalhÃEs, J. T. D., Marangoni, S., et al. (2015). Purification, partial characterization and antimicrobial activity of Lectin from Chenopodium Quinoa seeds. Food Sci. Technol. 35, 696-703. doi: 10.1590/1678-457x.6823

Richman, A., Swanson, A., Humphrey, T., Chapman, R., McGarvey, B., Pocs, R., et al. (2005). Functional genomics uncovers three glucosyltransferases involved in the synthesis of the major sweet glucosides of Stevia rebaudiana. Plant J. 41, 56-67. doi: 10.1111/j.1365-313X.2004.02275.x

Udompaisarn, S., Arthan, D., and Somana, J. (2017). Development and validation of an enzymatic method to determine stevioside content from Stevia rebaudiana. J. Agric. Food Chem. 65, 3223-3229. doi: 10.1021/acs.jafc.6b05793 
Wan, H.-D., Tao, G.-J., Kim, D., and Xia, Y.-M. (2012). Enzymatic preparation of a natural sweetener rubusoside from specific hydrolysis of stevioside with $\beta$-galactosidase from Aspergillus sp. J. Mol. Catal. B Enzym. 82, 12-17. doi: 10.1016/j.molcatb.2012.05.018

Wang, C., Tang, J., Qian, B., Zeng, Z., Gao, Y., and Song, J. L. (2020). Rubusoside alleviates the ovalbumin-induced mice allergic asthma by modulating the NF- $\kappa$ B activation. J. Food Biochem. 44:e13187. doi: 10.1111/jfbc.13187

Wang, W., Sun, Y., Peng, P., Gu, G., Du, G., Xu, L., et al. (2021). Two-step enzymatic conversion of rebaudioside a into a mono-alpha-1,4-glucosylated rebaudioside a derivative. J Agric. Food Chem. 69, 2522-2530. doi: 10.1021/acs. jafc.0c07452

Wang, Z., Wang, J., Jiang, M., Wei, Y., Pang, H., Wei, H., et al. (2015). Selective production of rubusoside from stevioside by using the sophorose activity of beta-glucosidase from Streptomyces sp. GXT6. Appl. Microbiol. Biotechnol. 99, 9663-9674. doi: 10.1007/s00253-015-6802-z

Xia, Y., Li, K., Li, J., Wang, T., Gu, L., and Xun, L. (2019). T5 exonucleasedependent assembly offers a low-cost method for efficient cloning and sitedirected mutagenesis. Nucleic. Acids. Res. 47:e15. doi: 10.1093/nar/gky1169

Zhang, F., Koh, G. Y., Hollingsworth, J., Russo, P. S., Stout, R. W., and Liu, Z. (2012). Reformulation of etoposide with solubility-enhancing rubusoside. Int. J. Pharm. 434, 453-459. doi: 10.1016/j.ijpharm.2012.06.013

Zhang, M., Dai, T., and Feng, N. (2017). A novel solubility-enhanced rubusosidebased micelles for increased cancer therapy. Nanoscale Res. Lett. 12:274. doi: 10.1186/s11671-017-2054-4
Zuo, G., and Hao, B. (2015). CVTree3 web server for whole-genome-based and alignment-free prokaryotic phylogeny and taxonomy. Genom. Proteom. Bioinform. 13, 321-331. doi: 10.1016/j.gpb.2015.08.004

Zuo, S. S., and Lundahl, P. (2000). A micro-bradford membrane protein assay. Anal. Biochem. 284, 162-164. doi: 10.1006/abio.2000. 4676

Conflict of Interest: The authors declare that the research was conducted in the absence of any commercial or financial relationships that could be construed as a potential conflict of interest.

Publisher's Note: All claims expressed in this article are solely those of the authors and do not necessarily represent those of their affiliated organizations, or those of the publisher, the editors and the reviewers. Any product that may be evaluated in this article, or claim that may be made by its manufacturer, is not guaranteed or endorsed by the publisher.

Copyright (c) 2021 Yan, Cao, Yang, Yang, Xu, Jiang and Xiao. This is an openaccess article distributed under the terms of the Creative Commons Attribution License (CC BY). The use, distribution or reproduction in other forums is permitted, provided the original author(s) and the copyright owner(s) are credited and that the original publication in this journal is cited, in accordance with accepted academic practice. No use, distribution or reproduction is permitted which does not comply with these terms. 